NBER WORKING PAPER SERIES

\title{
CHECK UP BEFORE YOU CHECK OUT: RETAIL CLINICS AND EMERGENCY ROOM USE
}

\author{
Diane Alexander \\ Janet Currie \\ Molly Schnell \\ Working Paper 23585 \\ http://www.nber.org/papers/w23585 \\ NATIONAL BUREAU OF ECONOMIC RESEARCH \\ 1050 Massachusetts Avenue \\ Cambridge, MA 02138 \\ July 2017, Revised July 2018
}

We thank participants in seminars at Princeton University, the University of Chicago, the 2017 Highland Health Economics Symposium, and the 2018 American Society of Health Economists Annual Meeting for helpful feedback. We also thank the staff at the New Jersey Department of Health for their assistance in accessing the data used in this paper. The Center for Health and Wellbeing at Princeton University provided generous financial support. All views expressed are those of the authors and cannot be attributed to the Federal Reserve Bank of Chicago, the Federal Reserve System, the New Jersey Department of Health, or the National Bureau of Economic Research.

NBER working papers are circulated for discussion and comment purposes. They have not been peer-reviewed or been subject to the review by the NBER Board of Directors that accompanies official NBER publications.

(C) 2017 by Diane Alexander, Janet Currie, and Molly Schnell. All rights reserved. Short sections of text, not to exceed two paragraphs, may be quoted without explicit permission provided that full credit, including $\odot$ notice, is given to the source. 
Check Up Before You Check Out: Retail Clinics and Emergency Room Use

Diane Alexander, Janet Currie, and Molly Schnell

NBER Working Paper No. 23585

July 2017, Revised July 2018

JEL No. I11

\section{ABSTRACT}

The retail clinic is an innovation that has the potential to improve competition in health care markets. Given concern about inefficient use of the emergency room (ER) increasing health care costs, we use all ER visits in New Jersey from 2006-2014 to examine the impact of retail clinics on ER usage. We find that people residing close to an open clinic are 4.1-12.3 percent less likely to use an ER for preventable conditions and for minor acute conditions. Our estimates suggest annual cost savings of over $\$ 70$ million from reduced ER usage if retail clinics were readily available across New Jersey.

Diane Alexander

Federal Reserve Bank of Chicago

11 th floor

230 S. LaSalle St.

Chicago, IL 60604

dalexander@frbchi.org

Janet Currie

Department of Economics

Center for Health and Wellbeing

185A Julis Romo Rabinowitz Building

Princeton University

Princeton, NJ 08544

and NBER

jcurrie@princeton.edu
Molly Schnell

Princeton University

Department of Economics

Julis Romo Rabinowitz Building

Princeton, NJ 08544

mollyks@princeton.edu 


\section{Introduction}

The U.S. health care market is often viewed as one in which competition does not work well: it is increasingly concentrated (Gaynor and Townsend, 2011); prices are not transparent; and many studies highlight imperfections and asymmetries in the information available to providers, patients, and insurers. These shortcomings are thought to entail large efficiency and welfare losses both from unnecessary procedures and delayed interventions, including costly emergency room (ER) visits that could have been avoided with proper preventive care.

Policy makers have long sought to increase competition in health care markets. For example, a joint commission of the Federal Trade Commission (FTC) and the Department of Justice (DOJ) recommended adopting measures to increase competition including increasing transparency in pricing and lowering barriers to entry into primary care for allied health professions (FTC and DOJ, 2004). In fact, expanded scope of practice laws allowing nurse practitioners to practice outside a doctor's office are thought to have been a key policy leading to the rise of retail clinics (Carton et al., 2016). In turn, retail clinics have been leaders in promoting price transparency. ${ }^{1}$

Retail clinics first appeared in 2000 and have since grown rapidly, with over 2,000 clinics operating in 41 states and Washington D.C. in 2015 (NCSL, 2017). Retail clinics are generally located within retail stores, such as pharmacies or "big-box" outlets like Wal-Mart. They offer a limited range of services and are staffed by nurse practitioners or physician assistants. Retail clinics are typically open seven days a week, have extended hours in the evenings, and do not require appointments. Prices are posted on line and may be a quarter to a third less expensive

\footnotetext{
${ }^{1}$ The commission recognized that competition is not a panacea. They state that "Competition cannot provide its full benefits to consumers without good information and properly aligned incentives. Moreover, competition cannot eliminate the inherent uncertainties in health care, or the informational asymmetries among consumers, providers, and payers. Competition also will not shift resources to those who do not have them" (FTC and DOJ, 2004).
} 
than the price a doctor would charge for the same services (Mehrotra et al., 2009; Tu and Cohen, 2008; Thygeson et al., 2008). Thus, retail clinics compete with doctors' offices for basic primary care services by offering lower and more transparent prices, shorter waiting times, and convenience (Ahmed and Fincham, 2010; Wang et al., 2010).

In this paper, we use the universe of visits to ERs in New Jersey between 2006 and 2014 to examine the impact of retail clinics on ER use. We focus on ER use because it is thought that many cases that end up in the ER reflect inefficient allocations of medical care, and reducing the unnecessary use of emergency services has long been a focus on public policy. ${ }^{2}$ Lowering the monetary and time costs of care might result in higher consumption of primary care and subsequent improvements in health which could be reflected in fewer ER visits. Retail clinics may also divert some patients from ERs, particularly for relatively minor conditions that arise outside of normal office hours when doctors' offices are typically closed, resulting in cost savings. On the other hand, professional physician organizations have expressed fears that retail clinics might sell unnecessary services or products, provide lower quality, or disrupt continuity of care, leading to higher costs and worse health outcomes including additional ER visits (AMA, 2007; AAP, 2014; AAFP, 201). In light of these concerns, the American Medical Association has called for greater regulation of store-based clinics.

In order to identify the effects of retail clinics on ER usage, we use a difference-indifference framework. In particular, we compare ER visits among residents living 0 to 2 miles from any site where a clinic ever operated ("near"), to those among residents who live 2 to 5

\footnotetext{
${ }^{2}$ For example, Kellermann and Weinick (2012) discuss Washington state's attempt to reduce Medicaid costs by restricting the use of ERs for non-urgent care. They argue that the policy ultimately failed because inappropriate use of ERs reflected lack of access to other sources of primary care. This is exactly the sort of deficiency that retail clinics could possibly remedy.
} 
miles from such a site ("far"), when the clinic is operating and when it is not. ${ }^{3}$ Our identifying assumptions are therefore that those who live closest to a clinic are most likely to use it, and that ER visits would have shown similar trends in both distance bands in the absence of the opening and/or closing of a retail clinic. We exclude patients who live further than 5 miles away from sites where a retail clinic ever operated over our sample period because patients in unserved areas are quite different than those in areas where retail clinics locate. To absorb any timeinvariant differences across neighborhoods, all of our specifications include a fixed effect for each retail clinic location.

We consider three classes of conditions: (1) conditions that frequently result in ER visits but which could have been prevented by adequate primary care; (2) relatively minor conditions which could nevertheless lead to an ER visit in the absence of an open or convenient doctor's office or retail clinic; and (3) a control group of conditions that are normally only treated in the ER and cannot be prevented by improved primary care. The first category of conditions-severe yet preventable conditions_-includes ER visits for influenza and complications of diabetes. These conditions are common reasons for ER visits and both flu shots and routine diabetes care are explicit foci of retail clinics. The second category—relatively minor conditions-includes sprains and strains, urinary tract infections, conjunctivitis, upper respiratory tract infections, ear infections, and sore throat. Finally, placebo conditions that cannot be treated in a retail clinic include fractures, poisonings, and childbirth.

We find that residents who live close to an open clinic are 12.3 percent less likely to go to the ER for influenza and 4.1 percent less likely to use the ER for complications of diabetes. They are also between 4.7 and 11.4 percent less likely to go to the ER for relatively common, minor

\footnotetext{
${ }^{3}$ Results are robust to using 0 to 1 vs. 1 to 3 mile bands.
} 
conditions. As predicted, retail clinics do not have any statistically significant effect on ER visits for fractures, poisonings, or childbirths.

Our estimates suggest that retail clinics result in annual cost savings of $\$ 817,492$ per 100,000 people from reduced ER use alone. Scaled to the population of New Jersey in 2010 $(8,791,894)$, these estimates suggest a potential cost savings from ER visits of over $\$ 70$ million annually. The bulk of these savings come from reductions in visits for the two preventable conditions we consider: Influenza and diabetes.

Two previous studies have suggested that retail clinics may increase health care costs by encouraging more primary care visits outside of the ER (Sussman et al., 2013; Ashwood et al., 2016). ${ }^{4,5}$ It is unclear whether cost savings from reduced ER visits completely offset increases in health care cost from additional visits to retail clinics. Since New Jersey does not have an "all payer claims" data base, it is in fact impossible to ask how outpatient visits have changed over time. However, we calculate that it would take over 700,000 annual visits to retail clinics in New Jersey, costing \$100/visit, to offset the estimated savings from reduced ER usage. Furthermore, to the extent that preventing illness is socially beneficial, even when such illnesses do not result in an interaction with the healthcare system, the fact that retail clinics reduce the burden of preventable diseases may swing the balance of welfare calculations in favor of regulatory changes that promote competition from retail clinics.

\footnotetext{
${ }^{4}$ One recent paper from the medical literature also looks at the effect of retail clinics on low acuity emergency room visits, and finds little to no effect (Martsolf et al., 2017). Our analysis differs from Martsolf et al. (2017) in a number of ways that could explain the discrepancy. For example, Martsolf et al. (2017) focus on the ratio of low acuity ER visits to other ER visits. If ER visits for both low acuity visits and other preventable conditions fall (as we argue), then they could find no effect or even a positive effect of retail clinics, as both the numerator and the denominator are affected by retail clinics. In contrast, we look at ER visits per capita. Our data are also richer, including both a finer level of geographical detail. Finally, we include ER visits that result in an admission to hospital which are excluded in Martsolf et al.

${ }^{5}$ Using a similar identification strategy to Martsolf et al. (2017), Hollingsworth (2014) shows that the number of retail clinics within 5 miles of a Florida hospital in 2012 is associated with fewer ER visits for bronchitis in 2012 relative to 2006 .
} 
Our paper improves on previous work in four ways. First, we consider the universe of patients who ever use an ER rather than a subset of patients who are covered by a particular insurance plan. This feature of our data ensures that we capture all of the changes in ER utilization that occur as a result of retail clinic operation. Second, we consider ER visits for an immunization preventable disease (influenza), a prevalent chronic condition (diabetes), low acuity conditions like sprains and strains, as well as a range of placebo conditions that are not treated in retail clinics and should therefore be unaffected, like childbirth. ${ }^{6}$ This range of conditions allows us to obtain a more complete picture of the impact of retail clinics on ER usage than previous work. Third, given the length of our panel, we are able to exploit both openings and closings of retail clinics. This rich variation in timing allows us to distinguish the effects of retail clinics from underlying trends in ER use. Finally, our difference-in-difference framework does not require us to match patients on observables. Our estimates are therefore not subject to the selection biases that result when matching does not perfectly control for differences between those who use retail clinics and those who do not.

This paper proceeds as follows. In Section 2, we provide additional background on retail clinics and discuss the categories of conditions that we consider. Section 3 introduces a conceptual framework that highlights the predicted impacts of retail clinic expansion on ER visits for preventable and non-preventable conditions of different severities. We discuss the datasets used in our analysis in Section 4. Section 5 outlines our empirical specification, and results are provided in Section 6. Section 7 discusses and concludes.

\footnotetext{
${ }^{6}$ Ashwood et al. (2016) note that it may be important to consider conditions that can be prevented through adequate primary care rather than only treatment for minor illnesses, but they do not do this.
} 


\section{Background}

Retail clinics are highly concentrated among just a few retailers: CVS MinuteClinics and Walgreen's Healthcare Clinics make up 75 percent of the market nationwide (market shares of 50 and 25 percent, respectively) with Kroger, Wal-Mart, and Target accounting for most of the rest (NCSL, 2016). ${ }^{7}$ In recent years, Wal-Mart and Target began to exit the retail clinic business; at the end of 2015, CVS acquired all of Target's pharmacies and in-store clinics for \$1.9 billion. In New Jersey, ShopRite closed all six of its locations between 2008 and 2012, while CVS opened at least two new stores in every year between 2011 and 2014.

Retail clinics are predominately staffed by nurse practitioners (NPs). Under New Jersey's scope of practice laws, NPs must be supervised by a doctor both to practice and to prescribe medication. However, the supervising doctor is not required to be on site. In practice, NPs adhere to a manualized practice handbook outlining protocols and refer to their supervising physician only when a situation requires further guidance. The use of NPs is a key difference between retail clinics and urgent care clinics. The later can be difficult to distinguish from traditional doctors' offices, since they are staffed by doctors and often take appointments in advance. In fact, for regulatory purposes urgent care clinics are treated as doctor's offices.

Prices charged by retail clinics are on average between 25-33 percent less expensive than the prices charged by physicians' offices for the same services (Mehrotra et al., 2009; Tu and Cohen, 2008). These cost savings are likely to be salient to consumers as retail clinics are used primarily by younger adults and families who are more likely to be uninsured and to pay out of pocket than those using other health care providers (ICPSR, 2010). However, most retail clinic

\footnotetext{
${ }^{7}$ CVS owns and operates all of its clinics while Walgreens outsources clinics to health care groups.
} 
visits are still covered by insurance, with about 70 percent of retail clinic customers being insured (compared to 90 percent for patients visiting primary care physicians).

Despite lower and more transparent prices, patients cite convenience (i.e. time costs) as the main reason for using retail clinics (Weinick et al., 2010). Almost all New Jersey retail clinics are open on weekends and weekday evenings, and every retail clinic in New Jersey has a pharmacy on site (see Table 1). Patients are generally seen on a first come, first served basis, although some clinics allow patients to make an appointment or "get in line" online before arriving at the clinic.

Retail clinics are very transparent about the types of medical care they can and cannot provide. Services include treating minor illnesses such as urinary tract infections, ear infections, conjunctivitis, and sore throat (see http://www.cvs.com/minuteclinic/services/minor-illnesses/N-

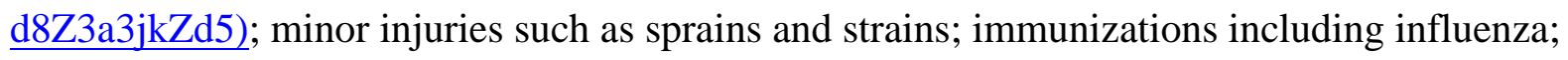
and health screenings such as diabetic glucose screenings. Retail clinics do not have imaging equipment or intravenous drips and are not equipped to handle fractures, childbirth, or lifethreatening emergencies such as poisonings.

In what follows, we examine the impact of retail clinics on ER visits for three sets of conditions: (1) emergent, preventable; (2) primary care treatable; and (3) emergent, not preventable. These three severity categories are in the spirit of those used in Billings et al. (2000) and Taubman et al. (2014). Our classification focuses on diagnoses that are both known to be treated in retail clinics and where there is little ambiguity in severity class. ${ }^{8}$ An overview of these condition categories and how their treatment relates to the services provided by retail clinics is

\footnotetext{
${ }^{8}$ The Billings et al. (2000) classification algorithm starts with very detailed medical records to determine what percentage of each diagnosis would fall into each severity category. The algorithm then applies this information to discharge records, where individual cases are classified probabilistically based on the percentage of cases with each discharge diagnosis that fell into each category in the more detailed data.
} 
given below.

\section{Emergent, Preventable Conditions}

The first group of conditions that we consider includes ER visits for influenza and complications of diabetes. We refer to this group as "emergent, preventable" since these conditions can be prevented with adequate primary care but often result in ER visits once they develop.

While visits for influenza represent a relatively small fraction of ER visits in New Jersey (0.21 percent; see Table 2), they are particularly important from a public health perspective. For each person whose influenza is sufficiently severe to be treated at a hospital, there are many more cases that result in visits to doctors' offices and an even larger number of cases that did not result in contact with health care providers but may have caused days missed from work or school. ${ }^{9}$ Moreover, there is a non-trivial risk of death from influenza. According to the Centers for Disease Control (CDC), annual U.S. deaths related to influenza ranged from 12,000 to 56,000 between 2010 and 2014 (CDC, 2018).

Retail clinics are particularly well placed to increase influenza vaccination rates and in turn to decrease the severity of seasonal outbreaks. One of the most common reasons adults give for foregoing the vaccine is that they forgot or "didn't get around to it" (Harris et al., 2010). When adults do get immunized, they receive the vaccination from many different sources, suggesting that convenience plays an important role. ${ }^{10}$ Located within high foot traffic stores, retail clinics are convenient and advertise to remind their shoppers to get a flu shot. According to one large retailer, over half of those immunized did not intend to get a flu shot when they entered

\footnotetext{
${ }^{9}$ It is estimated that for every flu hospitalization there are approximately 5.6 ER visits, 66 cases which sought medical care, and around 149 cases total (Kostova et al., 2013; Uscher-Pines and Elixhauser, 2013).

${ }^{10}$ According to the CDC (2012), while most children receive flu shots at doctors' offices or health centers (65 percent and 19 percent, respectively), more adults get vaccinated at pharmacies, stores, and workplaces than at a doctor's office.
} 
the store (Sifferlin, 2013). Anecdotal evidence further suggests that NPs routinely offer flu shots to retail clinic patients at the end of each visit. According to Uscher-Pines et al. (2012), vaccines were administered in 40 percent of visits to retail clinics from 2007 to 2009, with 95 percent of the vaccinations being for influenza. ${ }^{11}$

In addition to offering immunizations, retail clinics are increasingly advertising that they can provide monitoring for common chronic conditions, such as diabetes. Unlike influenza, complications of diabetes make up a large share of ER visits. In New Jersey, 8.74 percent of ER visits had diabetes listed as either a primary or secondary diagnosis (see Table 2). If properly managed, diabetes should not result in ER visits, and thus a reduction in ER visits for diabetes represents evidence of an improvement in primary care.

According to the U.S. National Library of Medicine's MedlinePlus, ${ }^{12}$ recommended care for diabetics includes two to three visits per year to monitor blood pressure, weight, and blood glucose levels (using A1C tests) and to check for any infections or loss of feeling in the feet. Diabetics must also monitor cholesterol and check for protein in the urine. The necessity for frequent visits for routine monitoring, combined with the many supplies (insulin, other drugs such as metformin, needles, testing strips) that must be purchased from pharmacies, make diabetics a natural market for retail clinics.

\section{Primary Care Treatable Conditions}

The second set of conditions that we consider includes the following minor conditions: urinary tract infection, conjunctivitis, upper respiratory tract infections, sore throat, ear infection, and

\footnotetext{
1155 percent of the vaccinations were administered to adults aged 18 to 64 . Patients who visit retail clinics specifically to receive influenza vaccinations are older and less likely to be black or Hispanic relative to the retail clinic patient population as a whole (Lee et al., 2009). This pattern likely reflects national differences in vaccination rates between racial and ethnic groups: vaccination rates for non-Hispanic whites are much higher than for blacks or Hispanics.

${ }^{12}$ Available at https://medlineplus.gov/ency/patientinstructions/000082.htm; last accessed July 2018.
} 
sprains and strains. We chose these six categories because they together account for the largest share of ER visits among minor illnesses and injuries (12.36 percent of ER visits in New Jersey over our sample period; see Table 2) and are all explicitly listed online as treated at CVS MinuteClinics (the majority of retail clinics in New Jersey; see Table 1).

\section{Emergent, Non-Preventable Conditions}

The third set of conditions that we examine are placebo conditions that retail clinics do not treat and that are not likely to be prevented by routine preventive care: fractures, childbirth, and poisonings. On their list of services, CVS MinuteClinics specifically tell patients with suspected poisonings not to seek care at their clinics. Furthermore, conversations with NPs at CVS MinuteClinics in New Jersey suggest that practitioners immediately send patients who arrive with a suspected broken bone to the ER. Finally, while retail clinics do provide limited family planning services, it is unlikely that retail clinics affect aggregate fertility patterns. ${ }^{13} \mathrm{We}$ therefore do not expect retail clinics to have any impact on the use of ERs for these services.

\section{Conceptual Framework}

In this section, we consider where patients choose to receive care. This decision depends on both the availability of different treatment options (ER, doctor's office, retail clinic) and the severity of the patient's condition. We start by assuming that there are no retail clinics, and ask how the availability of a primary care doctor influences ER usage. We then introduce retail clinics to ask how ER usage is affected by the presence of this new treatment option, both when a primary care doctor is available and when a primary care doctor is unavailable.

\footnotetext{
${ }^{13}$ While a short-term prescription for birth control can be obtained at a retail clinic, retail clinics are not intended to be a regular source of care for reproductive health. Anecdotal evidence suggests that NPs in New Jersey advise patients to follow up with an OB-GYN whenever a prescription for birth control is administered.
} 
All of the intuition presented below can be displayed graphically using value functions that depict the net benefit of care (benefit - cost) as a function of the patient's severity. In drawing these curves, we make three sets of assumptions. First, we assume that the value of treatment is weakly increasing in the severity of the patient's condition. Second, as there are bounds on both the costs and benefits of treatment, we assume that the value function is either concave or S-shaped. ${ }^{14}$ Finally, we assume that retail clinics are the most valuable treatment option (in terms of benefit minus costs) for patients with low-severity conditions, doctors' offices are the most valuable treatment option for patients with mid-severity conditions, and ERs are the most valuable treatment option for patients with high-severity conditions. ${ }^{15}$

\section{Without retail clinics}

In the absence of retail clinics, ER usage is determined by both the availability and the relative costs and benefits of receiving emergency versus primary care. When a primary care doctor is not available, either because it is after hours or because appointments are limited, patients will go to the ER only if the net value of receiving emergency care is greater than zero. ${ }^{16}$ Since the value of receiving care is weakly increasing in the severity of the patient's condition, only patients with severities exceeding some threshold will find it beneficial to go to an ER. This result is displayed

\footnotetext{
14 As drawn below, we assume that there is an inflection point in the value function for care received in either an ER or a doctor's office: while the marginal value of treatment is increasing at an increasing rate from low-severity to mid-severity conditions, the marginal value of treatment is increasing at a decreasing rate from mid-severity to highseverity conditions.

15 These relative values derive from underlying assumptions about the relative costs and benefits of receiving care in each location. In terms of costs, the evidence suggests that retail clinics are the lowest cost option, either because of direct monetary costs or time costs, whereas ERs are the most expensive option. In terms of benefits, since retail clinics only treat low-severity conditions, the benefits of receiving treatment for more severe conditions are greater at doctors' offices and ERs. Finally, since many high-severity conditions require emergency care, ERs are the most beneficial option for high-severity conditions.

${ }^{16}$ Recent work by Bruni et al. (2016) in Italy suggests that extending hours of primary care availability alone can generate significant reductions in the use of the ER.
} 
graphically in Figure 1: When neither a retail clinic nor a primary care doctor is available, only patients with severities exceeding $d$ will go to the ER (case 1).

When a primary care doctor is available but there is no retail clinic (case 2 in Figure 1), two things change: (1) more patients receive care and (2) fewer patients go to the ER. More patients receive care because it is beneficial for patients with relatively low-severity conditions to receive primary care but not emergency care ("market expansion"; patients with severities between $b$ and $d$ in Figure 1). If some of these patients receive preventive care, such as flu shots, then ER visits will also decline in the future from fewer patients developing high-severity conditions ("prevention"; some fraction of severities greater than $d$ in Figure 1). Finally, as it is more valuable for mid-severity patients to receive primary care than emergency care, even though mid-severity patients would go to an ER in the absence of available primary care, fewer patients go to the ER in the current period ("substitution"; patients with severities between $d$ and $f$ in Figure 1). ${ }^{17}$ Note that since the value of receiving emergency care exceeds the value of receiving primary care for high-severity conditions, high-severity patients will go the ER regardless of whether primary care is an option (patients with severities exceeding $f$ in Figure 1).

\section{With retail clinics}

How do retail clinics affect who receives treatment and in which health care setting the treatment is received? The impacts of retail clinics on the market when a primary care doctor is either unavailable or available are depicted in cases 3 and 4 of Figure 1, respectively. As with the

\footnotetext{
${ }^{17}$ Providing evidence of this substitution, Buchmueller et al. (2006) find that hospital closures in LA shifted some care to doctors' offices.
} 
introduction of a primary care doctor discussed above, retail clinics affect the market through three mechanisms: market expansion, prevention, and substitution.

Since retail clinics are more valuable than doctors' offices and ERs for low-severity conditions, more patients will receive care in the current period when a retail clinic is present (in Figure 1, patients with severities between $a$ and $b$ if a primary care doctor is available or between $a$ and $d$ if a primary care doctor is unavailable). If some of these patients receive preventive care, then a fraction of these patients will avoid developing high-severity conditions that would require emergency care in the future.

Finally, the entrance of a retail clinic will cause substitution between different types of health care providers. If a primary care doctor is available, low-severity patients will substitute from doctors' offices to retail clinics (patients with severities between $b$ and $c$ ). If a primary care doctor is unavailable, mid-severity patients will substitute from ERs to retail clinics (patients with severities between $d$ and $e$ ). Note that since the value of receiving treatment from a doctor's office or ER exceeds the value of receiving care at a retail clinic for more severe conditions, the presence of retail clinics does not affect the provision of care for these patients.

The theoretical framework outlined above delivers three testable predictions about ER visits:

1. Prevention: Fewer visits to ERs for emergent, preventable conditions. ER visits for highseverity conditions that can be prevented through adequate primary care should decrease when a retail clinic opens if retail clinics effectively expand consumption of preventive care.

2. Substitution from ERs for primary care treatable conditions: ER visits for low-severity conditions that can be treated at either an ER, a doctor's office, or a retail clinic should decrease when a retail clinic opens. 
3. No substitution from ERs for emergent, non-preventable conditions: ER visits for highseverity conditions that cannot be prevented by primary care and are not usually treated in a doctor's office or retail clinic should stay the same when a retail clinic opens.

In addition to predictions about the number of ER visits for conditions of various types, our theoretical framework delivers predictions on the average severity of conditions that continue to be treated in an ER in the presence of a retail clinic. Since patients with relatively low-severity primary care treatable conditions will substitute from ERs to retail clinics when a retail clinic opens, we expect the remaining primary care treatable cases that are seen in the ER to be of higher severity than before the retail clinic opened. However, since there is no reason to believe that increased prevention will affect the severity of patients who nevertheless develop emergent conditions, we do not expect the remaining emergent, preventable cases that are seen in the ER to be of a systematically different severity than before the clinic opening. Similarly, since ER cases for emergent, non-preventable conditions should be unaffected by the presence of a retail clinic, the average severity of these cases treated in an ER should remain the same after a retail clinic opens.

\section{Data}

Data for this study come from two main sources: (1) The location and operation dates of retail clinics in New Jersey from 2006 to 2014 are from Merchant Medicine, and (2) data on all visits to New Jersey ERs over the same time period are from the New Jersey Department of Health. We supplement these data with information from the 2010 Census and the five-year pooled (2008-2012) American Community Survey (ACS).

The data from Merchant Medicine include the geocoded locations of all retail clinics in 
New Jersey and each clinic's opening and/or closing dates. A total of 55 retail clinics operated in New Jersey at some point over our sample period: two clinics opened before 2006 and 53 opened between 2006 and 2014. By 2014, 18 retail clinics had closed. The majority of clinic openings occurred in 2006, 2007, 2008, and 2011, and there was an increase in closures during the great recession (Figure 3). ${ }^{18}$ There is a seasonal pattern to openings and closings, with openings frequently occurring towards the end of the year and closings concentrated in March. Figure 2 shows the locations of all the clinics in these data, whether they opened or closed during our sample period, and the ownership of the pharmacies. The clustering of locations along the I-95 corridor reflects the distribution of New Jersey's population.

The hospital discharge data come from the New Jersey Uniform billing records. These records are compiled by the state from information that all general medical and surgical hospitals are required to submit about every individual encounter with a patient. We include all records where there is an ER revenue code on the billing record; some of these visits resulted in admission to the hospital whereas others did not. ${ }^{19}$ In most cases, the patient was seen in the ER and then sent home. Importantly, these data include the address of each patient. We use this information to extract each patient's residential census block group using ArcGIS.

We create a panel at the retail clinic-week level by linking the retail clinic and ER data geographically. For each retail clinic in these data, we create two distance groups: (1) a near ("treated") group that consists of census block groups with centroids within 2 miles of the retail clinic and (2) a far ("control”) group that consists of census block groups with centroids between

\footnotetext{
${ }^{18}$ In interviews with retail clinic staff, we were told that some retail clinics closed over this time period because of difficulties retaining practitioners. The high demand for NPs outside of retail clinics, combined with the requirement that practitioners work nights and weekends, makes it difficult for some clinics to retain their providers.

${ }^{19}$ Some ER discharge data only includes information on ER visits resulting in admission. Our data includes all ER visits regardless of whether the visit resulted in an admission.
} 
2 and 5 miles from the retail clinic. ${ }^{20,21}$ The ER data are then collapsed into retail clinic-weekdistance group cells so that for each retail clinic-week we have the number of ER visits per 100,000 people residing within 0 to 2 and 2 to 5 miles of the clinic. ${ }^{22}$ Patients who reside more than 5 miles from a retail clinic are not considered in our analysis. As there is no obvious choice for how to define the distance bands, for robustness we replicate our results using distance bands of 0 to 1 miles for "near" and 1 to 3 miles for "far."

As can be seen in the first panel of Table 3, the demographic characteristics of those living more than 5 miles from a retail clinic location are different than those living in the other two distance groups. In particular, the population of the areas more than 5 miles from a clinic are poorer, older, and more rural than either of the other two distance groups, and thus we do not think these areas serve as a good control group for the areas closest to where clinics are opening. The second panel of Table 3 shows that in the first quarter of our data (when only two retail clinics were operating in New Jersey) the block groups more than 5 miles from a retail clinic also had more weekly ER visits per 100,000 residents across diagnosis groups. By dropping these areas from our analysis, we create a control group that is more similar to the treatment group. Figure 4 displays the resulting distance groups geographically.

Despite being more similar than block groups 5 or more miles away, the treatment and control groups are not entirely identical. ${ }^{23}$ The treatment block groups are wealthier, more densely populated, and have a lower fraction of black residents than the control groups. To

\footnotetext{
${ }^{20}$ Some households fall within the catchment area of two retail clinics. In these cases, households are counted in both retail clinic groups.

${ }^{21}$ An alternative "treated" group would be visits occurring outside of normal business hours. Unfortunately, we do not observe the exact time stamp in the discharge data.

${ }^{22}$ Population is from the 2010 Census and is aggregated from the census block group level. We note that intercensal population estimates are not available at the block group level.

${ }^{23}$ Table 3 further highlights that there is no difference in average distance to the closest ER across treatment and control groups.
} 
control for remaining differences in local demographics, we take the population-weighted average across block group-level demographics from the ACS within each distance group. We include these local demographic measures in all of our regressions and explore the key assumption of parallel pre-trends across the treatment and control groups using event study graphs.

As introduced in Section 2, our primary outcome measures are the number of ER visits for conditions within three categories: (1) emergent, preventable; (2) primary care treatable; and (3) emergent, not preventable. The particular conditions included in each category are chosen based on conditions that are actually treated in retail clinics (urinary tract infections, conjunctivitis, upper respiratory tract infections, pharyngitis, otitis externa/media, sprains and strains, influenza, and diabetes), and conditions that are never treated in retail clinics and thus serve as controls (fractures, poisonings, and births). The ICD-9 codes used to define each diagnosis category are provided in Table 2 .

All visits are categorized based on the primary diagnosis code with the exception of diabetes. In order to capture complications associated with poor disease management, we include visits with diabetes listed in any diagnosis field when coding diabetes visits (up to nine diagnoses can be listed for each visit). ${ }^{24} \mathrm{We}$ treat diabetes differently from the other diagnoses because it is a chronic disease with a high comorbidity burden that often complicates the management of other conditions. While diabetes can be controlled in an outpatient setting with adequate primary care, unstable diabetes is associated with a wide range of conditions that can result in hospitalizations.

\footnotetext{
${ }^{24}$ In contrast to the other conditions we consider, diabetes is most often recorded as a secondary-rather than a primary-diagnosis (see Figure A.1). For example, even if diabetes is the underlying cause of a person's heart failure, heart failure is usually listed as the primary diagnosis with diabetes listed as a secondary diagnosis. Table A.1 lists the most common primary diagnoses for visits in which diabetes is listed as a secondary diagnosis.
} 
For influenza, we look at both the total number of visits and the number of visits by patients in different age groups (ages 0-4, 5-17, 18-44, 45-64, and 65+). Age is particularly important to consider when studying influenza, as there are important differences across age groups in both the riskiness of the disease and in vaccination rates. ${ }^{25}$ Despite the CDC's recommendation that everyone aged six months and older get an annual flu vaccination, primeaged adults are much less likely to be vaccinated than other age groups, with vaccination rates around 30 percent versus over two thirds for young children and older adults (CDC).

In addition to the number of ER visits, we further consider the average severity of individuals arriving at the ER within each diagnosis category. Our main proxy for severity is the total list charges reported for each patient. ${ }^{26}$ List charges come from a hospital's charge mastera list of charges for all billable items — and are not the prices paid by either insurers or patients but rather the starting point for negotiations between hospitals and insurers. As such, list charges are the same for all patients who receive particular services at a given hospital whereas actual amounts paid vary depending on the individual's insurance (with the actual price generally being a negotiated fraction of the list price). Total list charges incurred during a visit therefore measure how much was done to a patient and are a proxy for severity.

Total list charges are an imperfect proxy, however, since hospitals could respond to retail clinic entry by changing their charge master. We think it is unlikely that hospitals respond in this way, immediately. Nevertheless, we consider the number of diagnoses recorded as an alternative severity proxy; cases with more comorbidities are on average more complicated and difficult to

\footnotetext{
${ }^{25}$ Very young children and the elderly are both the most likely to die from influenza and the most likely to be vaccinated.

${ }^{26}$ In principle we could also use admission to the hospital as another proxy for severity. However, for the conditions we consider very few cases result in admission, so there is little meaningful variation in this measure.
} 
treat. $^{27}$ As many primary care treatable conditions only have one diagnosis recorded, however, the number of diagnoses is a much less sensitive measure compared to total list charges. For each severity proxy, we create an average at the retail clinic-distance group-week level for visits in each diagnosis category.

\section{Empirical Specification}

Our difference-in-difference strategy compares the number of ER visits among residents living in areas near a retail clinic to those among residents living slightly farther away, both before and after a retail clinic opened or closed. For each retail clinic $c$, there are two observations per week: (1) the number of ER visits or average severity of patients who live within 2 miles of the retail clinic and (2) the same outcomes for patients living between 2 and 5 miles from the retail clinic. The second group provides a counterfactual for the group of people living near the retail clinic. Note that we use all locations where a retail clinic ever operated over our sample period when defining observations, whether the retail clinic was currently operating or not.

Two assumptions must hold for this research design to identify the causal effect of retail clinics on ER use. First, it must be true that conditional on being within a 5 mile radius of a clinic, people who live closer to a retail clinic are more likely to use it. Survey evidence supports this assumption. According to the 2010 Health Tracking Household Survey, 76 percent of families using retail clinics said the fact that "the location was more convenient than another source of care" was either a major (49 percent) of minor ( 27 percent) factor in choosing to use a retail clinic. In addition, Tu and Boukus (2013) report that the rate of retail clinic use was 40

\footnotetext{
${ }^{27}$ As illnesses and injuries tend to be more severe for older patients, we also experimented with the average age of patients and the fraction of patients over 80 years old. Since most visits for primary care treatable diagnoses are made by relatively young patients, there is unfortunately little meaningful variation in this measure for these conditions.
} 
percent higher for patients living less than 1 mile from a retail clinic relative to those living 1 to 5 miles away in $2010 .^{28}$

Since it is unclear exactly how far a typical consumer is willing to travel to use a retail clinic, we repeat our main analysis using distance groups of 0 to 1 and 1 to 3 miles in place of our primary groups of 0 to 2 and 2 to 5 miles. $^{29}$ The wider distance band definitions ( 0 to 2 and 2 to 5 miles around a retail clinic) draw larger areas into both treatment and control groups, reducing noise in our estimates of ER visit rates. However, if only people within 1 mile are actually more likely than people further away to use retail clinics, then using the wider distance band definition will lead us to underestimate the true treatment effect of retail clinics on ER use by included untreated areas in the treatment group. Alternatively, and perhaps more likely, if the true treated population decays with distance but is not zero by 2 miles away from the clinic, some of the population in the "far" distance group in our main specification are also treated. If some of the control group is in reality treated, our results will again underestimate the effects of retail clinics on ER use.

The second assumption we need to make for our research design to identify a causal effect is that the treatment and control groups would have shown similar trends in ER use in the absence of a retail clinic opening or closing. In order to probe this assumption, Figures 5 through 7 plot the average number of ER visits per 100,000 people for the near (treatment) and far (control) groups for primary care treatable conditions (Figure 5); emergent, preventable conditions (Figure 6); and emergent, non-preventable conditions (Figure 7). Both clinic openings and closings are considered events (with closings treated as the negative of openings with respect

\footnotetext{
28 The Tu and Boukus (2013) study is based on a very small sample, so exact magnitudes should be interpreted with caution.

${ }^{29}$ Figure A.2 demonstrates the distance bands used in both our primary analysis and robustness exercises for a specific example: a retail clinic located in North Arlington (near Newark).
} 
to event time), and month, year, and retail clinic fixed effects are first removed from the data.

The trends in ER visits between the near and far distance groups are reasonably similar before a clinic opens (or after it closes), suggesting that the parallel trends assumption is justified. Note that our "near" and "far" definitions refer to distance to a retail clinic, which is uncorrelated with the distance to the nearest ER so it is perhaps unsurprising that there are similar pretrends in ER use in the two groups. ${ }^{30}$

We estimate regressions of the following form:

(1) ER Visits/Pop $\left.{ }_{c t d}=\beta_{0}+\beta_{1} I[\text { near }]_{c d}+\beta_{2} I[\text { clinic open }]_{c t}+\beta_{3}\left(I[\text { near }]_{c d} * \text { I[clinic open }\right]_{c t}\right)+$ $\beta X_{c d}+\lambda_{c}+\lambda_{\text {month }}+\varepsilon_{c t d}$

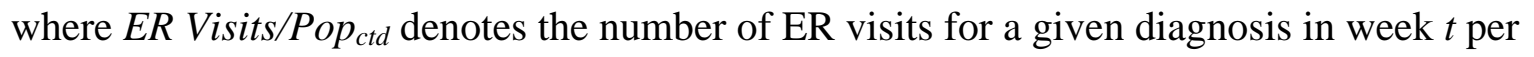
100,000 residents who live within distance group $d$ of retail clinic $c$. In some specifications, this dependent variable is replaced by average list charges. The variable I[ clinicopen $]_{c t}$ is an indicator equal to one if retail clinic $c$ is operating in week $t$ and zero otherwise for both distance groups associated with a clinic. The indicator $\mathrm{I}[\text { near }]_{c d}$ is equal to one for observations from the near category, regardless of whether the retail clinic is currently operating. Equation (1) further includes month by year and retail clinic location fixed effects to flexibly account for trends in hospital visits over time and differences across space. We also control for demographic characteristics in each retail clinic-distance group by including $X_{c d}$, a vector of populationweighted averages of block group demographic characteristics from the ACS. ${ }^{31}$ We further

\footnotetext{
${ }^{30}$ At the block group level, the correlation between the distance to the nearest open retail clinic and the nearest hospital-based emergency room is 0.036 .

31 Demographic controls include population density, fraction black, a quadratic in median household income, and the fraction of the population in detailed age bins $(5-9,10-14,15-17,18-24,25-34,35-44,45-54,55-64,65-74,75+)$.
} 
control for the distance from each retail clinic to the nearest hospital. ${ }^{32}$ Standard errors are clustered by retail clinic, and all of our regressions are population weighted. ${ }^{33}$

The parameter of interest in Equation (1) is $\beta_{3}$, the coefficient on the interaction term $\mathrm{I}[\text { near }]_{c d} * \mathrm{I}[\text { clinic open }]_{c t}$. This coefficient captures the differential impact of an open retail clinic on locations near the clinic relative to those further away. Given that our models include retail clinic fixed effects, $\beta_{3}$ is identified by changes in the operating status of a clinic (i.e., clinic openings and closings).

\section{Results}

Figures 5 and 6 show suggestive evidence of decreases in ER visits for influenza, diabetes, and a range of primary care treatable conditions in the treatment groups relative to the control groups in the months after a retail clinic opens. For diabetes and primary care treatable conditions, we see a widening of the gap between the near and far distance groups after a retail clinic opens. For influenza, the relationship between the near and far distance groups actually reverses: after a retail clinic opens, the near distance group switches from having more ER visits to having fewer ER visits relative to the far group. Reassuringly, Figure 7 demonstrates that no such pattern emerges among our placebo conditions. ${ }^{34}$

To more formally examine the impact of retail clinics on ER use, we estimate Equation (1). Results for the full sample are provided in Table 4. As can be seen in the first row, we do

\footnotetext{
${ }^{32}$ The distance between the retail clinic and the nearest hospital is time varying because of hospital closings. In principle we could run the analysis separately on areas that are near versus far from an ER, but unfortunately there is little variation in distance to the nearest hospital across population centers in New Jersey.

33 The qualitative patterns and statistical significance of our results are unaffected by weighting. Unweighted regression results are available upon request.

${ }^{34}$ The null results for the placebo conditions tell us two things: (1) trends in underlying health are not changing differentially in the treatment and control groups and (2) other changes in the provision of care that occurred over a similar time period, such as the expansion of urgent care centers and walk-in physician clinics, do not bias our results (as these types of clinics do treat some of the placebo conditions).
} 
not find a statistically significant main effect of a retail clinic being open for any condition. The main effect of being within 0-2 miles of a retail clinic is also statistically insignificant except for childbirth, confirming that the near and far groups have very similar patterns of ER use prior to clinic openings.

The coefficient of interest, the interaction term "Open*Near," behaves as predicted in our conceptual framework. Looking first to the results for emergent, preventable conditions, we see that ER visits for influenza fall by 13.6 percent and ER visits for diabetes fall by 3.6 percent among those near an open retail clinic (bottom panel of Table 4; columns 1 and 2). This later estimate is only significant at the 90 percent level of confidence, however. This pattern is in accordance with the prediction that ER visits for emergent, preventable conditions should decrease when a retail clinic opens due to increased use of preventive services.

Recall that ER visits for primary care treatable conditions are likewise predicted to fall among the near group when a retail clinic opens. As seen in the top panel of Table 4, we find significant negative interactions for all of the primary care treatable conditions we examine, indicating that people substitute away from ERs when a retail clinic is available. The reductions in ER visits for these minor conditions range from 5.7 percent (for urinary tract infections and sprains and strains) to 12 percent for sore throat. Finally, as predicted, we do not find any statistically significant effect of being near an open retail clinic on the placebo conditions of fractures, poisonings, and childbirth.

Table 5 probes the results for influenza further by estimating separate regressions by age. The results suggest that the largest effect (a 17 percent reduction in ER visits) is among adults aged 18-44, the group that previous work suggests is the most likely both to have low vaccination rates and to obtain a flu shot from a retail clinic. We also find large reductions in 
visits among children, suggesting either that they too get flu shots at retail clinics or that they benefit from reduced transmission among people their parents' age.

Figures 8, 9, and 10 show event study graphs for average list charges—our preferred proxy for severity. While average list charges are very similar in the near and far groups prior to the opening of a retail clinic for primary care treatable conditions, average list charges in the near areas are higher than those in the far areas after an opening (Figure 8). This finding provides suggestive evidence that the simplest cases in each primary care treatable condition substitute away from ERs to retail clinics, leaving the more complicated cases in the ER.

Perhaps unsurprisingly, Figure 9 provides little evidence of substitution for influenza. While increased vaccination should prevent flu cases from occurring in the first place, the serious flu cases that do emerge likely require hospital care, and thus there is no reason to believe that increased vaccination will affect the severity of the marginal patient who becomes infected and visits the ER. However, there is again suggestive evidence of some substitution away from ERs for the simplest diabetes cases starting around one year after the opening of a retail clinic. Finally, Figure 10 shows that for placebo conditions like fractures and childbirth, charges remain roughly the same in both near and far areas before and after clinic openings and closings.

Table 6 provides estimates of the effects of being near an open retail clinic on list charges for ER visits estimated in a regression similar to Equation (1). The results here are somewhat inconclusive. The interaction term "Open*Near" is uniformly positive, but it is only marginally statistically significant for urinary tract infections and otitis (ear ache). There is therefore some, albeit inconclusive, evidence that patients with less severe cases in these categories substitute 
from ERs to retail clinics to receive treatment. ${ }^{35}$

\section{Robustness}

The estimated effects of retail clinics on the number of ER visits when we instead use distance bands of 0-1 miles (near) and 1-3 miles (far) are provided in Table A.4. These estimates are somewhat noisier than those discussed above because there are many fewer people in the "near" band, but they show the same qualitative patterns. In particular, among those who live near an open retail clinic, we see reductions in ER visits for both influenza and a range of primary care treatable conditions. Our results are therefore robust to the use of alternative distance bands.

Qualified pharmacists in New Jersey have been able to administer vaccines to adults since 2004. ${ }^{36}$ However, in May 2014, New Jersey pharmacists gained the ability to administer the influenza vaccine to patients aged 7-17 with the permission of their parents or legal guardian and to patients under 12 with a prescription from an authorized provider (NJ Board of Pharmacy, 2015). All of our results are robust to including an indicator for the time period during which pharmacists were allowed to administer the flu vaccine to children or to dropping the last eight months of our sample. Furthermore, since we find the largest effect of retail clinics on ER flu visits for adults, we do not think that this change in the scope of practice of New Jersey pharmacists is confounding our main results.

A potential limitation of our work is that we have been unable to obtain information on the openings and closings of urgent care centers in New Jersey. As discussed above, urgent care

\footnotetext{
${ }^{35}$ Since the distribution of list charges is very skewed to the right, Table 6 is based on data that trims the top 0.1 percent of charges. Table A.2 shows estimates from regressions using untrimmed list charges. As an alternative approach to mitigating outliers, Table A.3 shows estimates from regressions in which list prices are first residualized from hospital fixed effects and an indicator denoting whether the patient was admitted. In both tables we again see suggestive evidence that less severe primary care treatable cases substitute away from ERs when a retail clinic is available.

36 Unfortunately, our hospital data does not go back far enough to look at the effect of allowing pharmacists to provide vaccinations on ER usage.
} 
centers differ from retail clinics in that they are staffed, run, and often owned by doctors, and price levels tend to be similar to doctor's offices (Mehotra et al., 2009). They also compete more directly with ERs in that they often offer services such as imaging and intravenous drips and can treat conditions such as simple fractures and poisonings. Like retail clinics, however, they offer patients convenience via walk-in appointments.

The key issue for our analysis is whether patients who live within 2 miles of a retail clinic are also more likely to live closer to an urgent care center than those who live 2-5 miles from a retail clinic. An analysis of the locations of urgent care centers in 2017 suggests that this is not the case: the number of urgent care centers per square mile is quite similar in the near and far distance bands (the locations of both are plotted in Figure A.3). Furthermore, if urgent care centers were opening in similar locations to retail clinics at similar times, we would find "effects" of retail clinics on fractures (which can be treated in urgent care centers but not retail clinics), which we do not. We therefore do not believe that the presence of urgent care centers biases our results regarding the impact of retail clinics.

\section{Discussion and Conclusions:}

Our study shows that retail clinics reduce ER visits both for minor conditions and for conditions like influenza and diabetes that are preventable given adequate primary care. These findings suggest that encouraging competition in the form of retail clinics, with their transparent prices and convenient access, has the potential to be welfare improving. Indeed, if Figure 1 is cast in terms of social benefits and social costs, then all of the visits between points $a$ and $b$ represent clear welfare improvements because these visits have positive value but would not have taken place in the absence of retail clinics. Likewise, the visits between points $b$ and $d$ have positive 
social value but would not have taken place when doctor's offices were closed in the absence of retail clinics. On the other hand, visits that are diverted from physicians' offices to retail clinics represent a transfer from one group to another and may be neutral in terms of welfare consequences. If, however, the net social cost of treatment (including costs due to congestion) is higher in the ER than elsewhere, then visits diverted from ERs to retail clinics (visits between points $d$ and $e$ in Figure 1) are likely to also be socially beneficial.

The difficulty that arises in making welfare calculations is that insured health care consumers do not pay the full cost of their care, so the private value (benefit minus cost for the patient) of the visit often exceeds the social value. This distortion in valuation means that patients may consume too much health care from a social perspective, and making consumption cheaper and easier should increase the size of this distortion.

Using our results, we can provide estimates of some of the costs and benefits of retail clinics on the healthcare system. First, we can compute the cost savings implied by the reductions in ER use that we observe. To do so, we use the cost data shown in Tables A.4 and A.5. As there is some evidence that visits for primary care treatable conditions that substitute from ERs to retail clinics are less severe, we use the $25^{\text {th }}$ percentile of costs to evaluate cost savings for these conditions. However, because improved preventive care should prevent visits for both minor and severe emergent, preventable conditions, we use mean costs for influenza visits and diabetes. Finally, because list prices overstate the actually amounts paid, we use an approximate cost-to-charge ratio drawn from Medicare of one third to deflate the estimated cost savings.

Combining these assumptions about cost with the estimated reductions in ER visits from Table 4, we estimate that an open retail clinic reduces spending on ER visits by at least $\$ 15,721$ 
per week per 100,000 people with convenient access to a clinic. This implies annual cost savings of $\$ 817,492$ per 100,000 , or $\$ 8.80$ per person. Of this amount, $\$ 7.60$ is accounted for by reductions in costs for ER visits due to influenza and diabetes.

This is likely an underestimate of the cost savings attributable to retail clinics for three reasons. First, we only consider two important preventable conditions that are easy to track in our data. However, increased access to primary care through retail clinic expansion likely reduces the burden of other emergent, preventable conditions. For example, there might well be important cumulative effects on conditions such as heart disease and stroke from more frequent monitoring of blood pressure and cholesterol levels. Second, we only consider the effect of retail clinics on ER visits. To the extent that we are missing savings in doctors' offices from better preventive care, as well as savings downstream from hospital visits such as those generated when patients are discharged into skilled nursing facilities or to home health care, the cost benefits of retail clinics will be greater. ${ }^{37}$ Third, as discussed above, to the extent that there is error in drawing the boundary between "near" and "far" areas, the estimated effects of residing near an open retail clinic will be attenuated. Further, Spetzl et al. (2013) argue that the costs of treating patients at retail clinics could be reduced further by loosening scope of practice laws that currently limit the services nurse NPs are allowed to provide.

According to Ashwood et al. (2016), retail clinics cause an increase in the number of visits for "low-acuity" conditions (conditions that we refer to as primary care treatable) that cost an additional $\$ 14$ per person after netting out reductions in ER visits for these conditions. ${ }^{38}$ Our results suggest that over half of this increased spending $(\$ 7.60)$ is offset by reductions in

\footnotetext{
${ }^{37}$ Around 1 percent of influenza and 9 percent of diabetes related ER visits are discharged to skilled nursing facilities.

${ }^{38}$ Ashwood et al. (2016) do not include sprains and strains in their measure of primary care treatable conditions, and so the increased spending of $\$ 14$ is not net of savings from substitution away from ERs for these conditions.
} 
preventable ER visits. Are these costs savings enough to overcome the costs of increased use?

While we cannot provide a definitive answer to this question, the fact that retail clinics appear to improve preventive care and prevent disease suggests that competition from retail clinics may well be welfare enhancing. To the extent that preventing sickness is socially beneficial, even when illness does not result in doctor visits, such considerations may swing the balance of welfare calculations in favor of policies promoting competition from retail clinics.

\section{References}

Ahmed, A. and J.E. Fincham. "Physician Office vs. Retail Clinic: Patient Preferences in Care Seeking for Minor Illnesses." Annals of Family Medicine, 2010, 8(2): 117-123.

American Academy of Family Physicians. "Retail Clinics." Technical report, 2014. URL http://www.aafp.org/about/policies/all/retail-clinics.html?cmpid=_van_587.

American Academy of Pediatrics. "AAP Principles Concerning Retail-Based Clinics." Technical Report, March 2014.

American Medical Association. "AMA Calls for Investigation of Store-Based Health Clinics." PR Newswire, June 2007. URL http://www.prnewswire.com/news-releases/ama-calls-forinvestigation-of-store-based-health-clinics-58310997.html.

Ashwood, J.S., M. Gaynor, C.M. Setodji, R.O. Reid, E. Weber, and A. Mehrotra. "Retail Clinic Visits For Low-Acuity Conditions Increase Utilization And Spending." Health Affairs, 2016, 35(3): 449-455.

Billings, J., N. Parikh, and T. Mijanovich. "Emergency Room Use: The New York Story." Commonwealth Fund, New York, 2000.

Bruni, M., I. Mammi, and C. Ugolini. "Does the Extension of Primary Care Practice Opening Hours Reduce the Use of Emergency Services?" Journal of Health Economics, 50: 144-155.

Buchmueller, T.C., M. Jacobson, and C. Wold. "How Far to the Hospital?: The Effect of Hospital Closures on Access to Care.” Journal of Health Economics, 2006, 25(4): 740-761.

Carthon, J.M.B., T. Sammarco, D. Pancir, J. Chittams, and K.W. Nicely. "Growth in RetailBased Clinics after Nurse Practitioner Scope of Practice Reform". Nursing Outlook, 2016.

Cooper, Z., F. Scott Morton, and N. Shekita. "Surprise! Out-of-Network Billing for Emergency Care in the United States." NBER Working Paper No. 23623, 2017. 
Gaynor, M. and R. Town. "Provider Competition," in Handbook of Health Economics, Volume 2, Borras, P., T. McGuire, and M. Pauly, eds., Amsterdam: Elsevier, 2011.

Harris, K.M., J. Maurer, L. Uscher-Pines, A.L. Kellermann, and N. Lurie. "Seasonal Flu Vaccination: Why Don't More Americans Get It?” Technical Report, RAND Corporation, 2010.

Hollingsworth, A. "Retail Health Clinics: Endogenous Location Choice and Emergency Department Diversion.” Indiana University School of Public and Environmental Affairs Working Paper, 2014.

Kellermann, A. and R. Weinick. "Emergency Departments, Medicaid Costs, and Access to Primary Care - Understanding the Link." New England Journal of Medicine, 2012, 366: 21412143.

Kostova, D., C. Reed, L. Finelli, P.Y. Cheng, P.M. Gargiullo, D.K. Shay, J.A. Singleton, M.I. Meltzer, P.J. Lu, and J.S. Bresee. "Influenza Illness and Hospitalizations Averted by Influenza Vaccination in the United States, 2005-2011.” PLoS ONE, 2013, 8(6).

Lee, B.Y., A. Mehrotra, R.M. Burns, and K.M. Harris. "Alternative Vaccination Locations: Who Uses Them and Can They Increase Flu Vaccination Rates?" Vaccine, 2009, 27(32): 42524256.

Martsolf, G., K.R. Fingar, R. Coffey, R. Kandrack, T. Charland, C. Eibner, A. Elixhauser, C. Steiner, and A. Mehrotra. "Association Between the Opening of Retail Clinics and Low-Acuity Emergency Department Visits.” Annals of Emergency Medicine, 2017, 69(4): 397-403.

Mehrotra, A., H. Liu, J.L. Adams, M.C. Wang, J.R. Lave, N.M. Thygeson, L.I. Solberg, and E.A. McGlynn. "Comparing Costs and Quality of Care at Retail Clinics with that of Other Medical Settings for 3 Common Illnesses." Annals of Internal Medicine, 2009, 151(5): 321-328.

National Conference of State Legislatures. "Retail Health Clinics: State Legislation and Laws." Technical Report, January 2016. URL http://www.ncsl.org/research/health/retail-health-clinicsstate-legislation-and-laws.aspx.

NJ Board of Pharmacy. "NJ Board of Pharmacy Law." Technical Report, October 2015. URL http://www.njconsumeraffairs.gov/Statutes/pharmacylaw.pdf.

Sifferlin, A. "Flu Shots at the Pharmacy: What you Need to Know," Time, September 2013. URL http://healthland.time.com/2013/09/04/flu-shots-at-the-pharmacy-what-you-need-to-know/.

Spetzl, J., S. Parente, R. Town, D. Bazarko. "Scope-of-Practice Laws for Nurse Practitioners Limit Cost Savings that Can be Achieved in Retail Clinics." Health Affairs, 2013, 32(11): 19771984.

Taubman, S.L., H.L. Allen, B.J. Wright, K. Baicker, A.N. Finkelstein. "Medicaid Increases Emergency-Department Use: Evidence from Oregon's Health Insurance Experiment." Science, 2014, 343(6168): 263-268. 
Thygeson, M., K.A. Van Vorst, M.V. Maciosek, and L. Solberg. "Use and Costs of Care in Retail Clinics vs. Traditional Care Sites.” Health Affairs, 2008, 27(5): 1284-1892.

Tu, H.T. and E.R. Boukus. "Despite Rapid Growth, Retail Clinic use Remains Modest." Technical Report, Center for Studying Health System Change, 2013.

Tu, H.T. and G.R. Cohen. "Checking Up on Retail-Based Health Clinics: Is the Boom Ending?" Technical Report, Center for Studying Health System Change, 2008.

U.S. Centers for Disease Control and Prevention. "Flu Vaccination Coverage, National Flu Survey." Technical Report, 2012.

U.S. Centers for Disease Control and Prevention. "Estimated Influenza Illnesses, Medical Visits, Hospitalizations, and Deaths Averted by Vaccination in the United States." Technical Report, 2017. URL https://www.cdc.gov/flu/about/disease/2015-16.htm.

U.S. Centers for Disease Control and Prevention. "Estimating Seasonal Influenza-Associated Deaths in the United States." Technical Report, 2018. URL https://www.cdc.gov/flu/about/disease/us_flu-related_deaths.htm.

U.S. Department of Justice and Federal Trade Commission. "Improving Health Care: A Dose of Competition.” Technical Report, U.S. Government Printing Office, July 2004.

Uscher-Pines, L. and A. Elixhauser. "Emergency Department Visits and Hospital Inpatient Stays for Seasonal and 2009 H1N1 Influenza, 2008-2009." Statistical Brief \#147, Agency for Healthcare Research and Quality, 2013

Uscher-Pines, L., K.M. Harris, R.M. Burns, and A. Mehrotra. "The Growth of Retail Clinics in Vaccination Delivery in the U.S." American Journal of Preventive Medicine, 2012, 43(1): 6366.

Wang, M.C., G. Ryan, E.A. McGlynn, and A. Mehrotra. "Why do Patients Seek Care at Retail Clinics, and What Alternatives Did they Consider?" American Journal of Medical Quality, 2010, 25(2): 128-134.

Weinick, R.M., C.E. Pollack, M.P. Fisher, E.M. Gillen, and A. Mehrotra. "Policy Implications of the Use of Retail Clinics.” Technical Report, RAND Corporation, 2010. 


\section{Figures}

Figure 1: Value of Treatment by Severity of Illness and Location

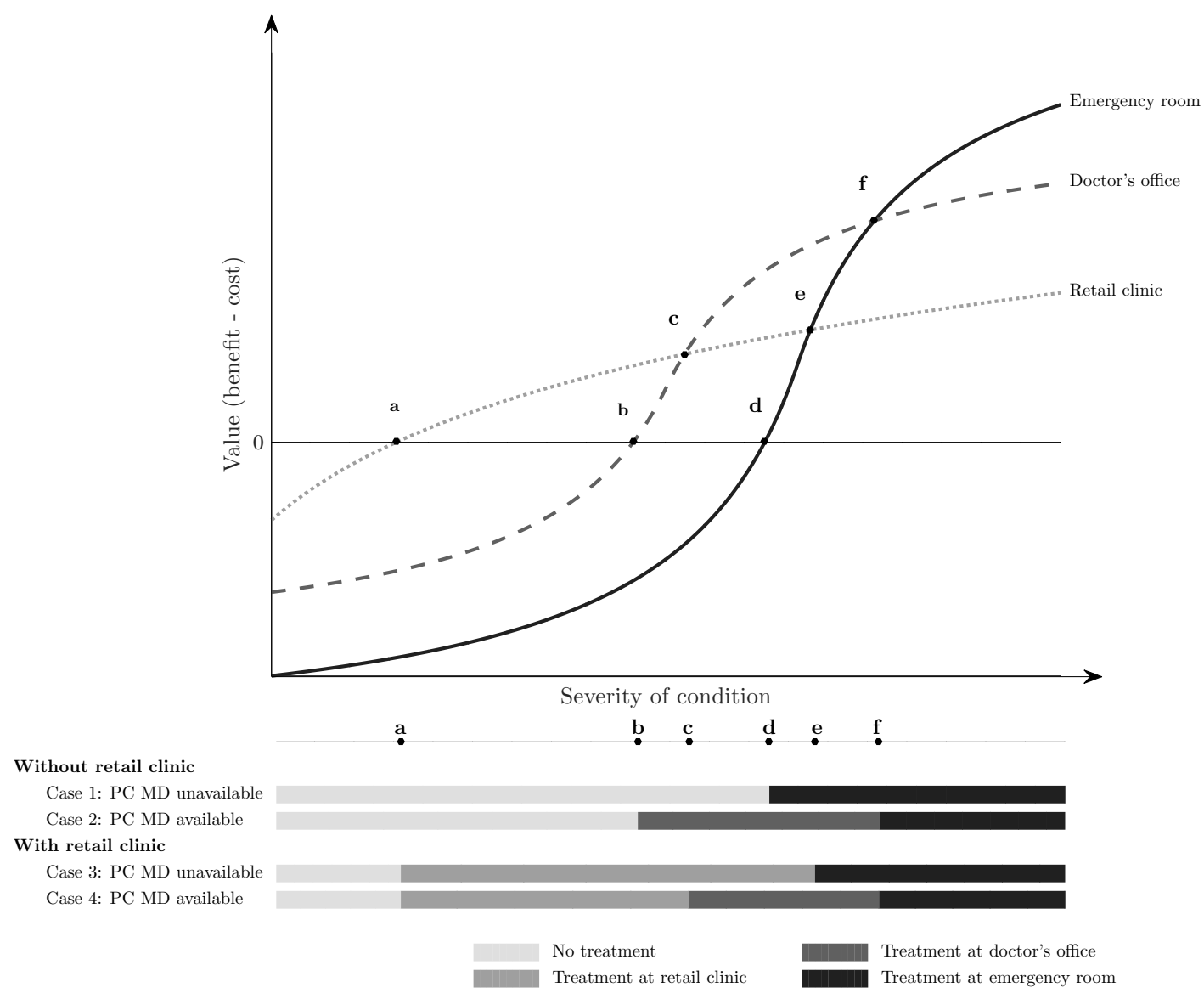

Notes: The top panel of the above figure depicts the value of care (benefit - cost) as a function of patient severity at retail clinics, doctors' offices, and ERs. The bottom panel displays in which locations patients of different severities choose to seek care in different states of the world (a primary care MD is available or unavailable; a retail clinic is available or unavailable). 
Figure 2: New Jersey Retail Clinics: Locations and Ownership
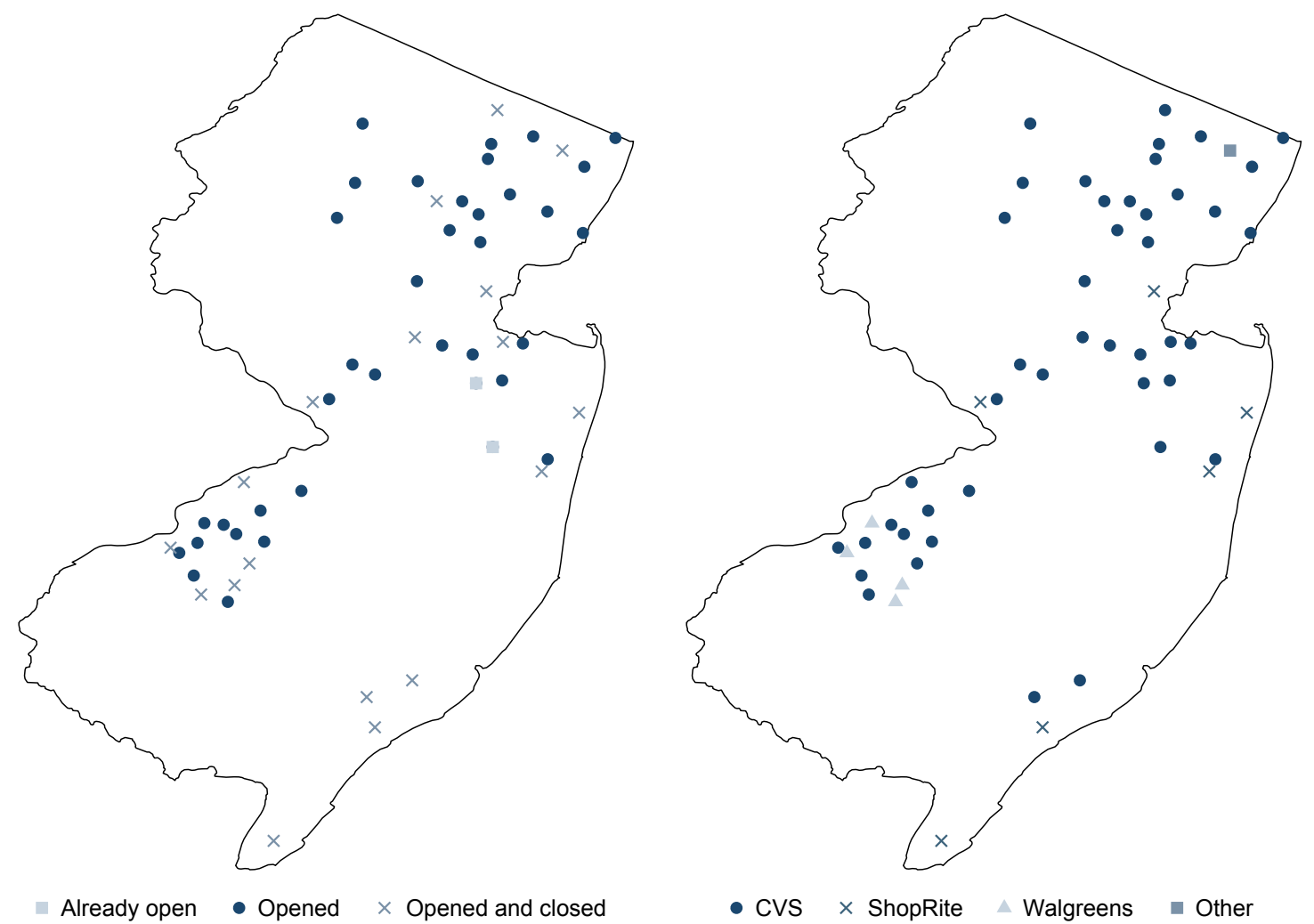

Notes: The above maps display the location, operation status between 2006 and 2014, and ownership of all retail clinics in New Jersey. As seen in the map on the left, two clinics were open before 2006, 53 opened between 2006 and 2014, and 18 opened and closed between 2006 and 2014. The single retail clinic not operated by CVS, ShopRite, or Walgreens was called Simple Simon Pharmacy. 
Figure 3: New Jersey Retail Clinics: Timing of Openings and Closings

By Year

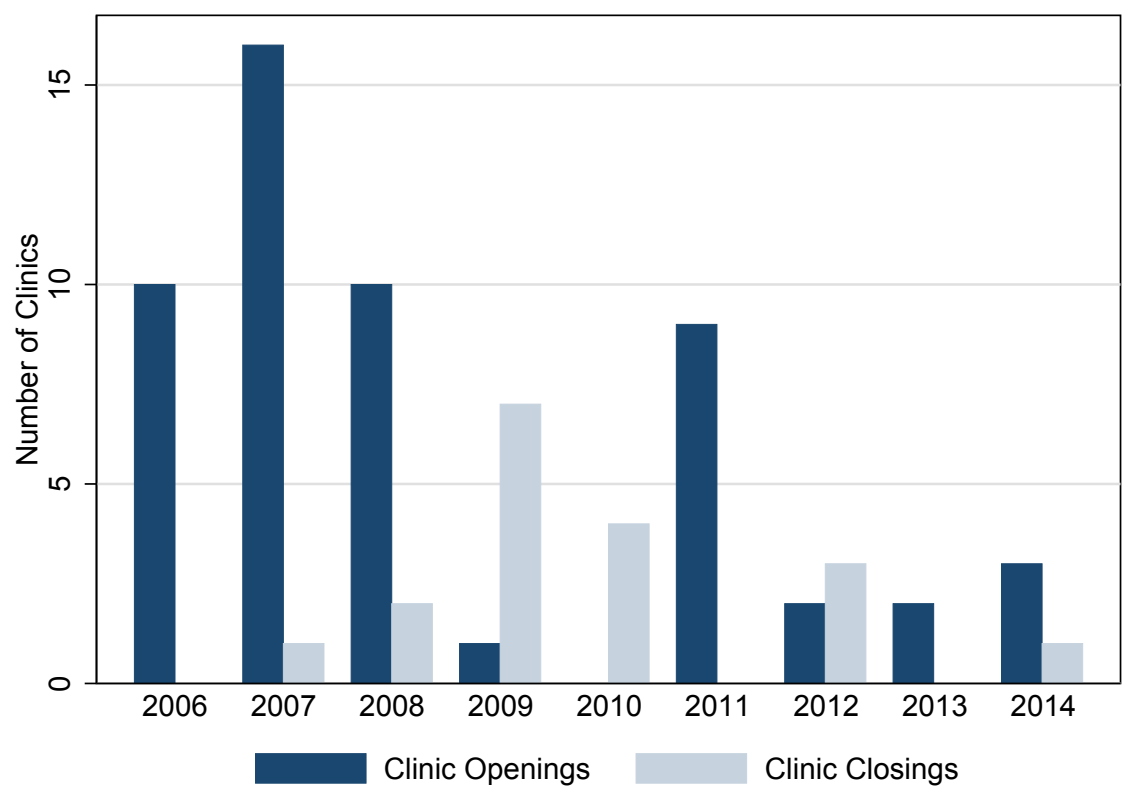

By Month

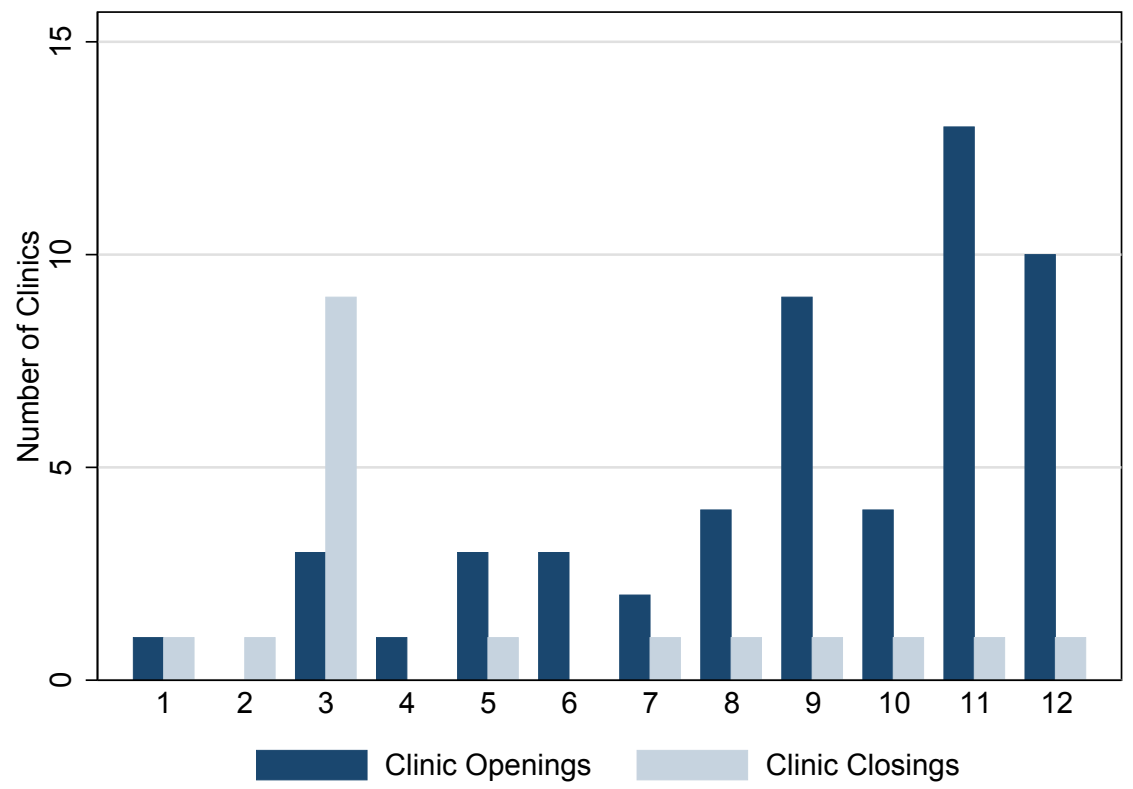

Notes: The above figures display the years and months in which retail clinics opened and closed in New Jersey between 2006 and 2014. 
Figure 4: New Jersey Retail Clinic Distance Groups: 0-2 Miles vs. 2-5 Miles

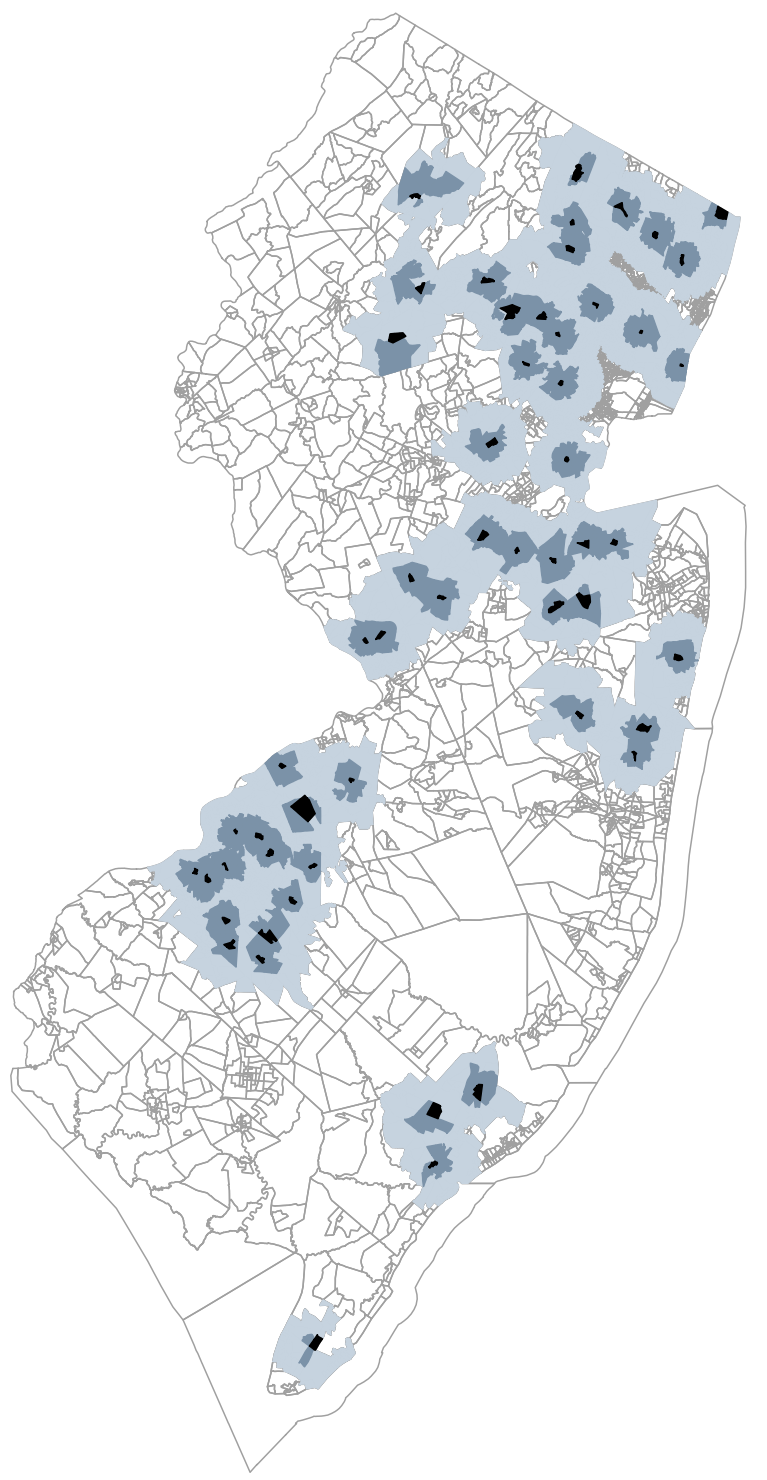

Notes: The above map displays the distance bands used in our analysis. The black block groups contain a retail clinic. The rings of block groups are shaded lighter as one moves away from a retail clinic and depict distances between 0 to 2 miles and 2 to 5 miles from each retail clinic. 
Figure 5: Primary Care Treatable Conditions: Difference in ER Visits Between Near and Far Distance Groups in Event Time

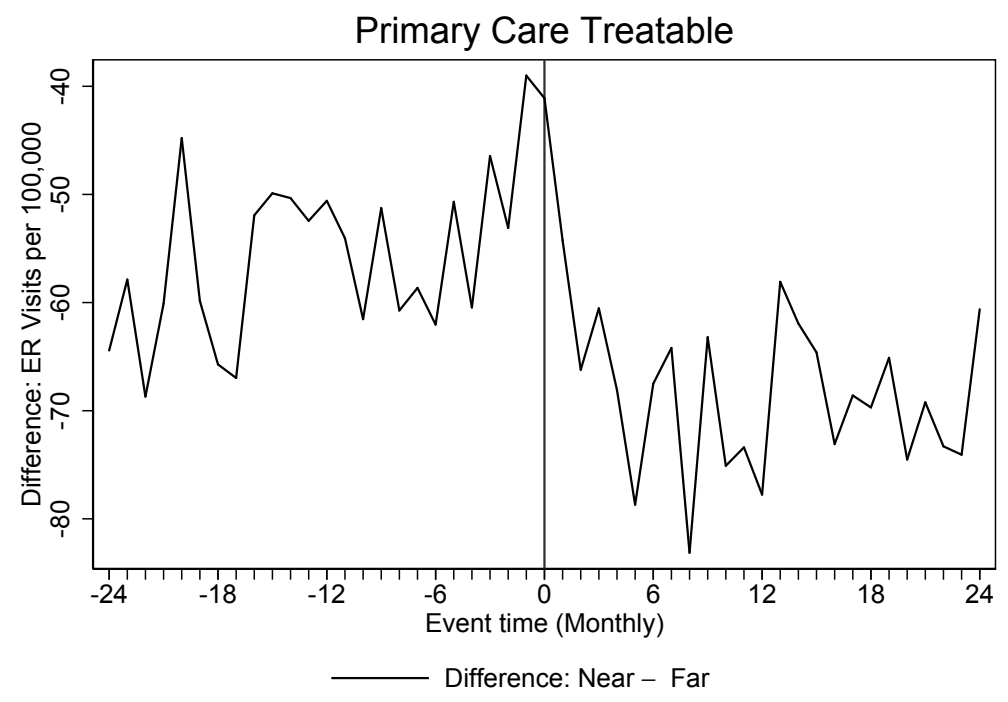

Notes: The above figure plots the difference in ER visits per 100,000 between the near and far distance groups in event time for a balanced panel. Coefficients from a regression of monthly ER visits on an indicator for near, event time dummies, and event time dummies interacted with near, as well as month by year and retail clinic fixed effects. An event is defined as either a clinic opening or closing (clinic closings are treated inversely to clinic openings). "Primary care treatable" is the sum of ER visits for urinary tract infections, conjuctivitis, upper repiratory tract infections, pharyngitis, otitis media, and sprains and straings. Population weighted.

Figure 6: Emergent, Preventable Conditions: ER Visits in Event Time
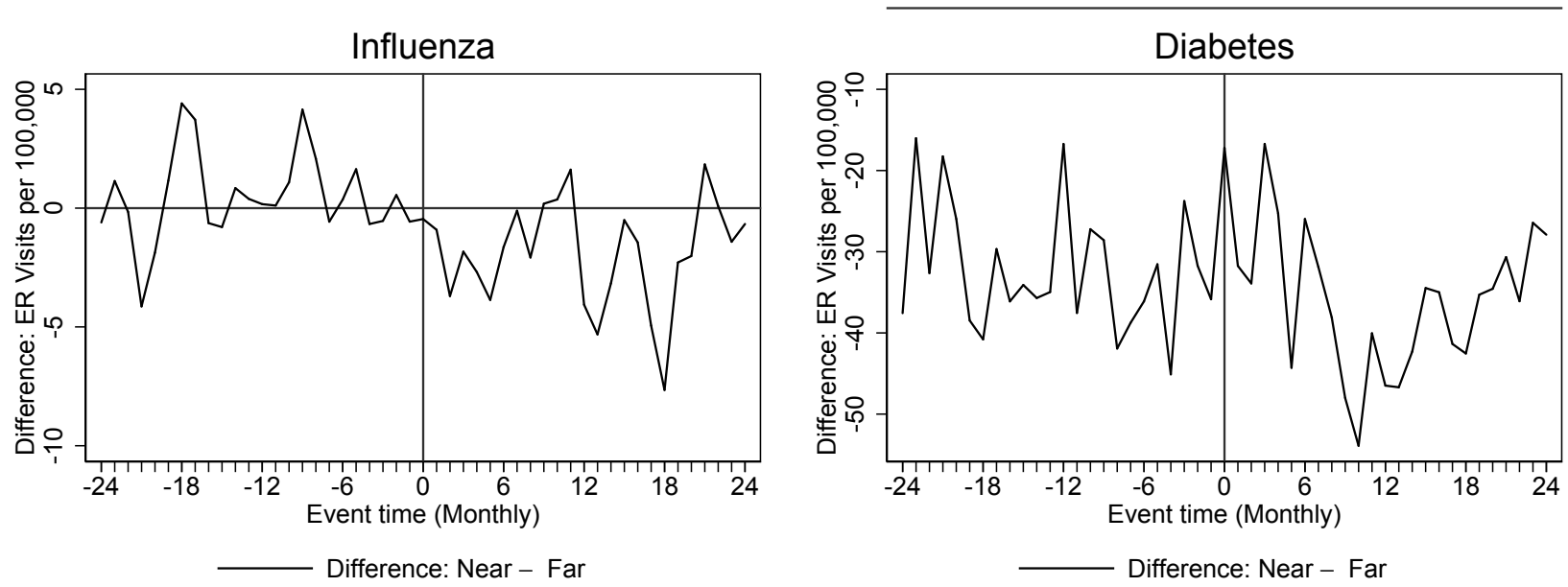

Notes: The above figure plots the difference in ER visits per 100,000 between the near and far distance groups in event time for a balanced panel. Coefficients from a regression of monthly ER visits on an indicator for near, event time dummies, and event time dummies interacted with near, as well as month by year and retail clinic fixed effects. An event is defined as either a clinic opening or closing (clinic closings are treated inversely to clinic openings). Population weighted. 
Figure 7: Emergent, Non-Preventable Conditions (Placebo): ER Visits in Event Time

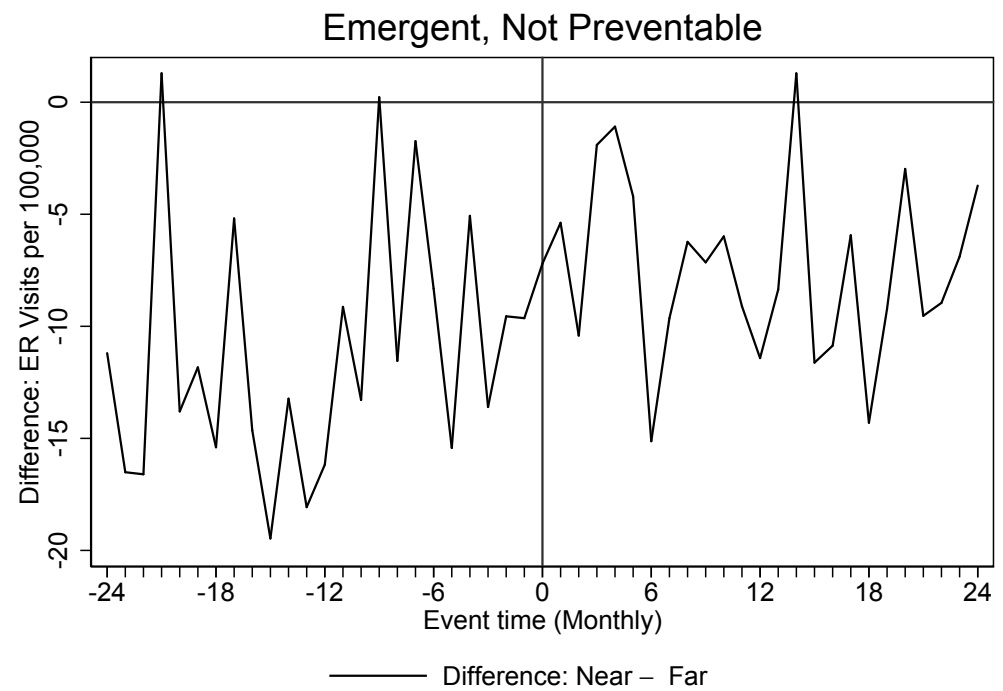

Notes: The above figure plots the difference in ER visits per 100,000 between the near and far distance groups in event time for a balanced panel. Coefficients from a regression of monthly ER visits on an indicator for near, event time dummies, and event time dummies interacted with near, as well as month by year and retail clinic fixed effects. An event is defined as either a clinic opening or closing (clinic closings are treated inversely to clinic openings). Population weighted. "Emergent, Not Preventable" is the sum of ER visits for fractures, births, and poisonings. 
Figure 8: Primary Care Treatable Conditions: List Charges in Event Time

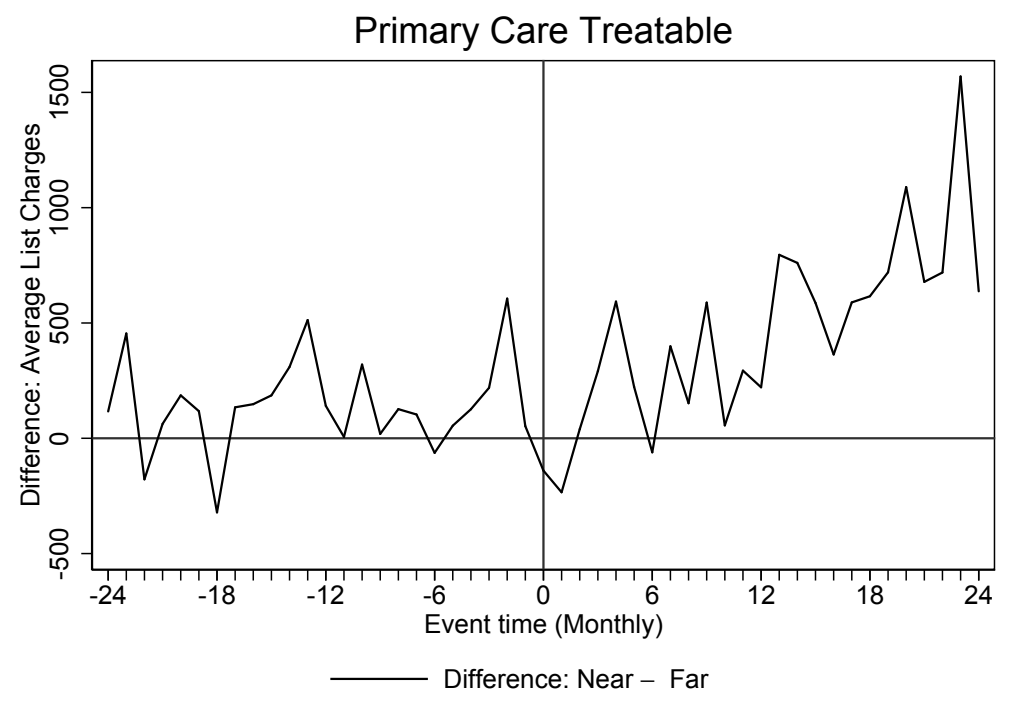

Notes: The above figure plots the difference in average monthly list charges between the near and far distance groups in event time for a balanced panel. Coefficients from a regression of average monthly list charges on an indicator for near, event time dummies, and event time dummies interacted with near, as well as month by year and retail clinic fixed effects. An event is defined as either a clinic opening or closing (clinic closings are treated inversely to clinic openings). "Primary care treatable" includes ER visits for urinary tract infections, conjuctivitis, upper repiratory tract infections, pharyngitis, otitis media, and sprains and straings. Population weighted.

Figure 9: Emergent, Preventable Conditions: List Charges in Event Time
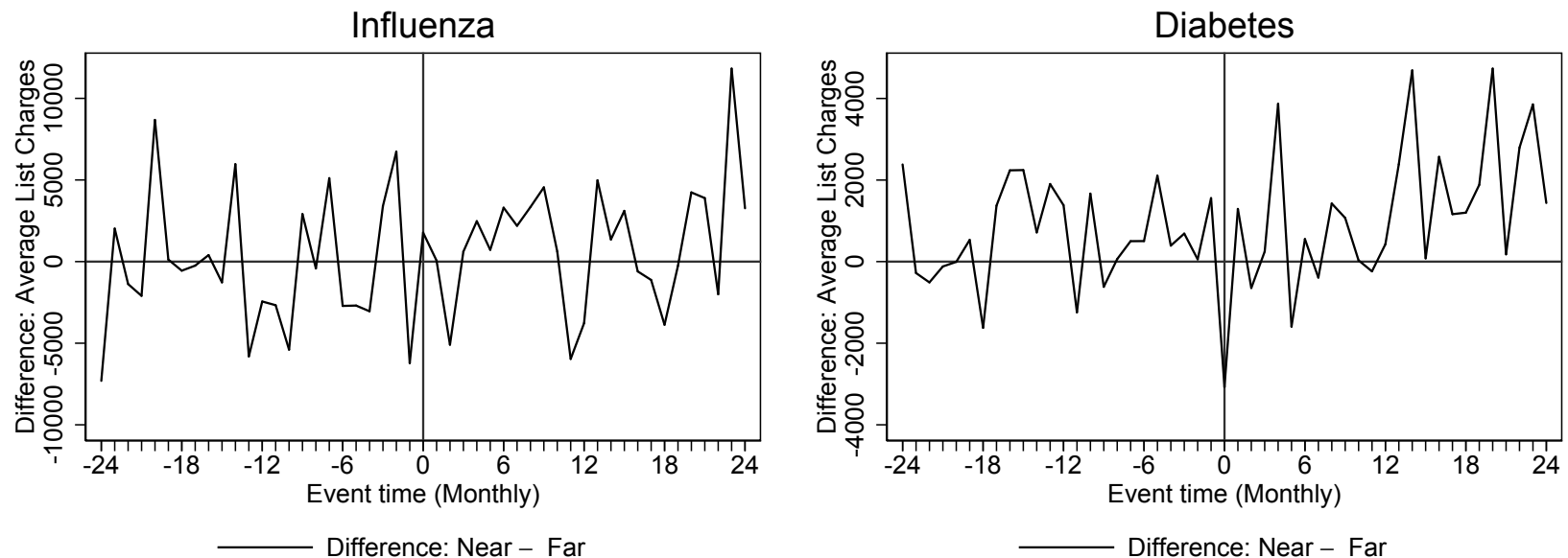

Notes: The above figure plots the difference in average monthly list charges between the near and far distance groups in event time for a balanced panel. Coefficients from a regression of average monthly list charges on an indicator for near, event time dummies, and event time dummies interacted with near, as well as month by year and retail clinic fixed effects. An event is defined as either a clinic opening or closing (clinic closings are treated inversely to clinic openings). 
Figure 10: Emergent, Non-Preventable Conditions (Placebo): List Charges in Event Time

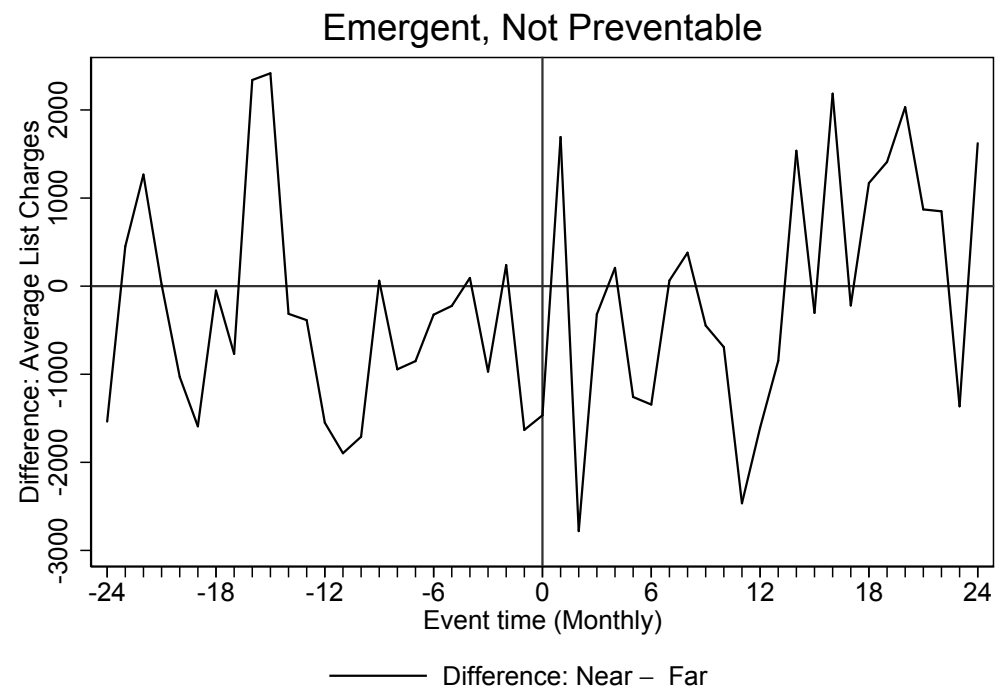

Notes: The above figure plots the difference in average monthly list charges between the near and far distance groups in event time for a balanced panel. Coefficients from a regression of average monthly list charges on an indicator for near, event time dummies, and event time dummies interacted with near, as well as month by year and retail clinic fixed effects. An event is defined as either a clinic opening or closing (clinic closings are treated inversely to clinic openings). "Emergent, Not Preventable" includes ER visits for fractures, births, and poisonings. 


\section{Tables}

Table 1: New Jersey Retail Clinics: Summary Statistics

\begin{tabular}{lccccc}
\hline & $(1)$ & $(2)$ & $(3)$ & $(4)$ & $(5)$ \\
& All & CVS & ShopRite & Walgreens & Other \\
\hline Open Saturdays & 0.96 & 0.98 & 0.83 & 1.00 & 1.00 \\
Open Sundays & 0.95 & 0.98 & 0.83 & 1.00 & 0.00 \\
Pharmacy on Site & 1.00 & 1.00 & 1.00 & 1.00 & 1.00 \\
Clinics Shut Down & 0.33 & 0.23 & 1.00 & 0.25 & 1.00 \\
\hline Weekday Open Time & $08: 32$ & $08: 30$ & $09: 20$ & $08: 00$ & $08: 00$ \\
Weekday Close Time & $07: 33$ & $07: 30$ & $08: 00$ & $07: 30$ & $08: 00$ \\
Saturday Open Time & $09: 02$ & $09: 00$ & $09: 00$ & $09: 30$ & $09: 00$ \\
Saturday Close Time & $05: 25$ & $05: 30$ & $05: 00$ & $05: 00$ & $06: 00$ \\
Sunday Open Time & $09: 48$ & $09: 55$ & $09: 00$ & $09: 30$ &. \\
Sunday Close Time & $05: 18$ & $05: 25$ & $04: 24$ & $05: 00$ &. \\
\hline Clinics & 55 & 44 & 6 & 4 & 1 \\
\hline
\end{tabular}

Notes: The above table summarizes characteristics of all retail clinics in operation in New Jersey at some point between 2006 and 2014. The "Other" category is Simple Simon Pharmacy. 
Table 2: Overview of Condition Categories

\begin{tabular}{lll}
\hline Diagnosis group & \multicolumn{1}{c}{$\begin{array}{c}\text { ICD-9-CM } \\
\text { codes }\end{array}$} & $\begin{array}{c}\text { Percent of } \\
\text { ER visits }\end{array}$ \\
\hline Primary care treatable & & \\
Urinary tract infection & $599^{*}, 595^{*}$ & $1.71 \%$ \\
Conjunctivitis & $372^{*}$ & $0.46 \%$ \\
URTI/sinusitis/bronchitis & $460^{*}-461^{*}, 465^{*}-466^{*}, 473,490$ & $3.15 \%$ \\
Pharyngitis & $462^{*}-463^{*}, 034$ & $1.37 \%$ \\
Otitis externa/media & $380^{*}-382^{*}$ & $1.39 \%$ \\
Sprains/strains & $840^{*}-848^{*}$ & $4.38 \%$ \\
Emergent, preventable & & \\
Influenza & $487^{*}-488^{*}$ & $0.21 \%$ \\
Diabetes & $249^{*}-250^{*}$ & $8.74 \%$ \\
Emergent, not preventable & & \\
Fractures & $800^{*}-829^{*}$ & $2.94 \%$ \\
Poisonings & $909.0^{*}, 909.1^{*}, 909.5^{*}, 995.2^{*}, 960^{*}-989^{*}$ & $0.53 \%$ \\
Childbirth & DRGs $372-375$ & $2.20 \%$ \\
\hline
\end{tabular}

Notes: The above table provides an overview of the three categories of conditions used in our analysis. For all conditions other than diabetes, we consider a visit as being for the condition in question only if the condition is listed as the primary diagnosis. For diabetes, we consider all visits in which diabetes is listed in any diagnosis field. The percent of ER visits reflects the total share of ER visits in New Jersey between 2006 and 2014 with the corresponding ICD-9 codes. 
Table 3: Retail Clinic Distance Groups: Block Group Summary Statistics at Baseline Demographics

\begin{tabular}{|c|c|c|c|c|c|}
\hline & $\begin{array}{l}(1) \\
\text { All }\end{array}$ & $\begin{array}{c}(2) \\
0-1 \text { Miles }\end{array}$ & $\begin{array}{c}(3) \\
0-2 \text { Miles }\end{array}$ & $\begin{array}{c}(4) \\
\text { 2-5 Miles }\end{array}$ & $\begin{array}{c}(5) \\
5+\text { miles }\end{array}$ \\
\hline Population & 1,391 & 1,372 & 1,361 & 1,385 & 1,415 \\
\hline Population density & 9,148 & 12,318 & 11,463 & 9,338 & 7,721 \\
\hline Median household income & 75,367 & 84,990 & 82,236 & 76,900 & 69,311 \\
\hline Pct. black & 14.36 & 7.54 & 10.83 & 15.81 & 13.37 \\
\hline Pct. under 18 & 23.06 & 21.16 & 22.13 & 23.51 & 22.67 \\
\hline Pct. aged 18-54 & 50.71 & 54.44 & 52.49 & 51.03 & 49.28 \\
\hline Pct. aged 55-74 & 19.33 & 17.63 & 18.68 & 18.89 & 20.44 \\
\hline Pct. age 75 and over & 6.90 & 6.77 & 6.70 & 6.57 & 7.61 \\
\hline Urgent care clinic density & 0.15 & 0.27 & 0.19 & 0.16 & 0.11 \\
\hline Distance to hospital & 2.93 & 2.38 & 2.36 & 2.37 & 4.20 \\
\hline Block Groups & 6,320 & 260 & 894 & 3,499 & 1,927 \\
\hline \multicolumn{6}{|c|}{ ER Visits per 100,000 per Week } \\
\hline & (1) & $(2)$ & (3) & (4) & $(5)$ \\
\hline & All & 0-1 Miles & 0-2 Miles & 2-5 Miles & $5+$ miles \\
\hline Urinary tract infection & 13.973 & 19.401 & 14.377 & 13.715 & 14.257 \\
\hline Conjuctivitis & 4.400 & 3.513 & 3.808 & 4.371 & 4.730 \\
\hline Upper repiratory infection & 38.250 & 28.266 & 31.919 & 37.756 & 42.116 \\
\hline Pharyngitis & 14.459 & 10.807 & 12.479 & 14.174 & 15.906 \\
\hline Otitis & 15.293 & 10.951 & 12.240 & 15.461 & 16.414 \\
\hline Sprain/strain & 41.032 & 36.823 & 37.608 & 39.512 & 45.416 \\
\hline Influenza & 1.899 & 1.307 & 1.632 & 1.894 & 2.033 \\
\hline Diabetes & 73.206 & 62.932 & 67.636 & 70.834 & 80.151 \\
\hline Fracture & 26.119 & 24.701 & 24.767 & 25.973 & 27.020 \\
\hline Poisoning & 4.130 & 3.376 & 3.987 & 4.091 & 4.269 \\
\hline Births & 21.735 & 25.080 & 21.483 & 21.860 & 21.623 \\
\hline Block Groups & 6,320 & 260 & 894 & 3,499 & 1,927 \\
\hline
\end{tabular}

Notes: The above table provides baseline demographic information and outcomes for block groups in different distance bands around retail clinics in New Jersey. Observations are at the block group level. Baseline weekly ER visits per 100,000 are the weekly rates averaged over the first quarter of our sample. Data is taken from both the 2010 Census and the 2008-2012 ACS. 
Table 4: Retail Clinics and ER Visits

\begin{tabular}{lcccccc}
\hline & \multicolumn{5}{c}{ Primary Care Treatable } \\
& $(1)$ & $(2)$ & $(3)$ & $(4)$ & $(5)$ & $(6)$ \\
& UTI & Conjunct. & URI & Pharyngitis & Otitis & Sprain/strain \\
\hline Open & 0.117 & 0.228 & 1.077 & 0.189 & 0.251 & 1.104 \\
& $(0.308)$ & $(0.146)$ & $(0.841)$ & $(0.490)$ & $(0.325)$ & $(0.693)$ \\
Near & -0.041 & 0.151 & -0.064 & 0.082 & -0.138 & 1.738 \\
& $(0.455)$ & $(0.200)$ & $(1.032)$ & $(0.566)$ & $(0.497)$ & $(1.088)$ \\
Open*Near & $-0.890^{* *}$ & $-0.402^{* *}$ & $-1.597^{*}$ & $-1.435^{* *}$ & $-0.715^{*}$ & $-2.289^{* * *}$ \\
& $(0.390)$ & $(0.179)$ & $(0.879)$ & $(0.619)$ & $(0.421)$ & $(0.813)$ \\
\hline Mean per 100k & 15.615 & 4.011 & 27.152 & 11.942 & 12.140 & 39.662 \\
Mean Pop. & 175,121 & 175,121 & 175,121 & 175,121 & 175,121 & 175,121 \\
R-Squared & 0.521 & 0.454 & 0.732 & 0.661 & 0.642 & 0.679 \\
Observations & 51,480 & 51,480 & 51,480 & 51,480 & 51,480 & 51,480 \\
\hline \hline
\end{tabular}

Emergent, Preventable Placebo: Emergent, Not Preventable

(1) (2)

(3)

(4)

(5)

\begin{tabular}{lccccc} 
& Influenza & Diabetes & Fracture & Poisoning & Births \\
\hline Open & 0.028 & -0.321 & 0.216 & 0.053 & -0.267 \\
& $(0.120)$ & $(1.183)$ & $(0.327)$ & $(0.102)$ & $(0.301)$ \\
Near & 0.102 & 0.816 & 0.706 & 0.054 & $-0.668^{* *}$ \\
& $(0.078)$ & $(1.937)$ & $(0.560)$ & $(0.136)$ & $(0.282)$ \\
Open*Near & $-0.251^{* * *}$ & $-2.526^{*}$ & -0.555 & -0.117 & 0.548 \\
& $(0.088)$ & $(1.441)$ & $(0.439)$ & $(0.102)$ & $(0.425)$ \\
\hline Mean per 100k & 1.878 & 76.390 & 27.495 & 5.064 & 20.804 \\
Mean Pop. & 175,121 & 175,121 & 175,121 & 175,121 & 175,121 \\
R-Squared & 0.502 & 0.790 & 0.458 & 0.401 & 0.616 \\
Observations & 51,480 & 51,480 & 51,480 & 51,480 & 51,480 \\
\hline
\end{tabular}

$* * * \mathrm{p}<0.01, * * \mathrm{p}<0.05, * \mathrm{p}<0.1$

Notes: Observations are at the retail clinic-distance band-week level. The independent variable in each regression is the number of ER visits for a given condition. All regressions include month byyear and retail clinic fixed effects and are population weighted. Additional retail clinic-distance group controls include population density, fraction black, a quadratic in median household income, distance to nearest hospital, and the age structure. Standard errors are clustered by retail clinic. "UTI" denotes urinary tract infections; "URTI" denotes upper respiratory tract infections. 
Table 5: Retail Clinics and ER Visits for Flu by Patient Age

\begin{tabular}{lcccccc}
\hline & $(1)$ & $(2)$ & $(3)$ & $(4)$ & $(5)$ & $(6)$ \\
& All Visits & Ages 0-4 & Ages 5-17 & Ages 18-44 & Ages 45-64 & Ages 65+ \\
\hline Open & 0.028 & -0.002 & -0.038 & 0.051 & 0.044 & -0.026 \\
& $(0.120)$ & $(0.582)$ & $(0.270)$ & $(0.105)$ & $(0.050)$ & $(0.066)$ \\
Near & 0.102 & $0.594^{*}$ & $0.272^{*}$ & 0.057 & -0.008 & -0.013 \\
& $(0.078)$ & $(0.334)$ & $(0.157)$ & $(0.102)$ & $(0.039)$ & $(0.060)$ \\
Open*Near & $-0.251^{* * *}$ & $-0.818^{*}$ & $-0.369^{* *}$ & $-0.325^{* * *}$ & -0.080 & 0.051 \\
& $(0.088)$ & $(0.420)$ & $(0.176)$ & $(0.107)$ & $(0.065)$ & $(0.089)$ \\
\hline Mean per 100k & 1.878 & 5.655 & 2.734 & 1.942 & 0.864 & 0.929 \\
Mean Pop. & 175,121 & 11,781 & 30,037 & 66,860 & 46,345 & 22,901 \\
R-Squared & 0.502 & 0.333 & 0.355 & 0.460 & 0.351 & 0.358 \\
Observations & 51,480 & 51,480 & 51,480 & 51,480 & 51,480 & 51,480 \\
\hline
\end{tabular}

*** $\mathrm{p}<0.01,{ }^{* *} \mathrm{p}<0.05, * \mathrm{p}<0.1$

Notes: Observations are at the retail clinic-distance band-week level. The independent variable in each regression is the number of ER visits for influenza. All regressions include month by year and retail clinic fixed effects and are population weighted. Additional retail clinic-distance group controls include population density, fraction black, a quadratic in median household income, distance to nearest hospital, and the age structure. Standard errors are clustered by retail clinic. 
Table 6: Retail Clinics and Average ER List Charges

\begin{tabular}{lcccccc}
\hline \multicolumn{7}{c}{ Primary Care Treatable } \\
\cline { 2 - 7 } & UTI & Conjunct. & URTI & Pharyngitis & Otitis & Sprain/strain \\
\hline Open & -330.317 & 35.972 & 79.040 & 90.786 & 9.320 & 47.755 \\
& $(230.307)$ & $(50.100)$ & $(83.881)$ & $(76.526)$ & $(58.924)$ & $(89.175)$ \\
Near & -458.965 & -68.730 & 3.980 & -28.656 & -23.843 & -20.575 \\
& $(279.216)$ & $(107.253)$ & $(154.260)$ & $(105.415)$ & $(95.942)$ & $(104.054)$ \\
Open*Near & $847.679^{*}$ & 165.461 & 427.660 & 234.627 & $327.419^{*}$ & 247.593 \\
& $(504.357)$ & $(214.460)$ & $(294.260)$ & $(217.165)$ & $(191.895)$ & $(210.771)$ \\
\hline Mean per 100k & $12,794.461$ & $1,220.547$ & $3,899.715$ & $1,788.249$ & $1,829.747$ & $2,667.661$ \\
Mean Pop. & 175,121 & 175,121 & 175,121 & 175,121 & 175,121 & 175,121 \\
R-Squared & 0.087 & 0.130 & 0.129 & 0.153 & 0.103 & 0.383 \\
Observations & 51,480 & 51,480 & 51,480 & 51,480 & 51,480 & 51,480 \\
\hline \hline
\end{tabular}

\begin{tabular}{|c|c|c|c|c|c|}
\hline & \multicolumn{2}{|c|}{ Emergent, Preventable } & \multicolumn{3}{|c|}{ Emergent, Not Preventable (Placebo) } \\
\hline & $(1)$ & $(2)$ & $(3)$ & $(4)$ & $(5)$ \\
\hline & Influenza & Diabetes & Fractures & Poisonings & Births \\
\hline \multirow[t]{2}{*}{ Open } & -214.543 & -388.686 & -347.490 & 27.087 & 91.058 \\
\hline & $(997.012)$ & $(362.217)$ & $(340.134)$ & $(429.094)$ & $(464.000)$ \\
\hline \multirow[t]{2}{*}{ Near } & $-2,119.802$ & -427.187 & -457.786 & -625.744 & -266.211 \\
\hline & $(1,315.987)$ & $(414.853)$ & $(318.818)$ & $(427.497)$ & $(221.921)$ \\
\hline \multirow[t]{2}{*}{ Open*Near } & $1,827.985$ & 764.090 & 467.331 & 886.099 & 389.109 \\
\hline & $(1,246.891)$ & $(642.152)$ & $(455.722)$ & $(624.454)$ & $(379.694)$ \\
\hline Mean per $100 \mathrm{k}$ & $7,996.014$ & $33,997.848$ & $17,587.116$ & $15,256.463$ & $23,120.788$ \\
\hline Mean Pop. & 175,121 & 175,121 & 175,121 & 175,121 & 175,121 \\
\hline R-Squared & 0.037 & 0.404 & 0.137 & 0.064 & 0.569 \\
\hline Observations & 51,480 & 51,480 & 51,480 & 51,480 & 51,480 \\
\hline
\end{tabular}

$* * * \mathrm{p}<0.01, * * \mathrm{p}<0.05, * \mathrm{p}<0.1$

Notes: Observations are at the retail clinic-distance band-week level. The independent variable in each regression is the average total list charges of ER visits for a given condition. Hospital visits with list charges at or above the 99.99th percentile across all ER visits for a given condition are excluded. All regressions include month, year, and retail clinic fixed effects and are population weighted. Additional retail clinic-distance group controls include population density, fraction black, a quadratic in median household income, and the age structure. Standard errors are clustered by retail clinic. "UTI" denotes urinary tract infections; "URTI" denotes upper respiratory tract infections. 
Table 7: Retail Clinics and ER Visits: 0-1 Miles vs. 1-3 Miles

\begin{tabular}{lcccccc}
\hline \multicolumn{7}{c}{ Primary Care Treatable } \\
\cline { 2 - 7 } & $(1)$ & $(2)$ & $(3)$ & $(4)$ & $(5)$ & $(6)$ \\
& UTI & Conjunct. & URTI & Pharyngitis & Otitis & Sprain/strain \\
\hline Open & -0.011 & 0.296 & 1.057 & -0.038 & 0.255 & 1.230 \\
Near & $(0.432)$ & $(0.214)$ & $(0.930)$ & $(0.639)$ & $(0.371)$ & $(0.899)$ \\
& 0.327 & $0.337^{*}$ & $1.650^{*}$ & 0.253 & 0.576 & $2.117^{* *}$ \\
Open*Near & $-0.430)$ & $(0.190)$ & $(0.985)$ & $(0.611)$ & $(0.415)$ & $(1.000)$ \\
& $(0.660)$ & $(0.225)$ & $(1.381)$ & $(0.864)$ & $(0.485)$ & $(1.158)$ \\
\hline Mean per 100k & 15.080 & 3.733 & 25.141 & 11.000 & 10.988 & 39.391 \\
Mean Pop. & 79,154 & 79,154 & 79,154 & 79,154 & 79,154 & 79,154 \\
R-Squared & 0.386 & 0.352 & 0.648 & 0.564 & 0.506 & 0.580 \\
Observations & 51,480 & 51,480 & 51,480 & 51,480 & 51,480 & 51,480 \\
\hline \hline
\end{tabular}

Emergent, Preventable Emergent, Not Preventable (Placebo)

(1)

$(2)$

(3)

(4)

(5)

\begin{tabular}{lccccc} 
& Influenza & Diabetes & Fractures & Poisonings & Births \\
\hline Open & -0.248 & -0.853 & 0.303 & 0.017 & 0.143 \\
& $(0.154)$ & $(1.450)$ & $(0.445)$ & $(0.158)$ & $(0.271)$ \\
Near & $0.171^{* *}$ & 1.798 & 0.556 & 0.181 & $-0.730^{* *}$ \\
& $(0.084)$ & $(2.315)$ & $(0.449)$ & $(0.131)$ & $(0.288)$ \\
Open*Near & $-0.305^{*}$ & -0.180 & -0.171 & 0.030 & 0.706 \\
& $(0.153)$ & $(2.625)$ & $(0.448)$ & $(0.163)$ & $0.438)$ \\
\hline Mean per 100k & 1.803 & 75.452 & 27.523 & 4.990 & 19.199 \\
Mean Pop. & 79,154 & 79,154 & 79,154 & 79,154 & 79,154 \\
R-Squared & 0.162 & 0.727 & 0.304 & 0.238 & 0.226 \\
Observations & 51,480 & 51,480 & 51,480 & 51,480 & 51,480 \\
\hline
\end{tabular}

*** $\mathrm{p}<0.01, * * \mathrm{p}<0.05, * \mathrm{p}<0.1$

Notes: Observations are at the retail clinic-distance band-week level. In contrast to our primary analysis, the near (far) group is within 0-1 (1-3) miles of a retail clinic; residents living further than 3 miles from a retail clinic are excluded. The independent variable in each regression is the number of ER visits for a given condition. All regressions include month, year, and retail clinic fixed effects and are population weighted. Additional retail clinic-distance group controls include population density, fraction black, a quadratic in median household income, and the age structure. Standard errors are clustered by retail clinic. "UTI" denotes urinary tract infections; "URTI" denotes upper respiratory tract infections. 


\section{Appendix}

\section{A Supplementary Figures}

Figure A.1: Diagnosis Number of Diabetes and Influenza
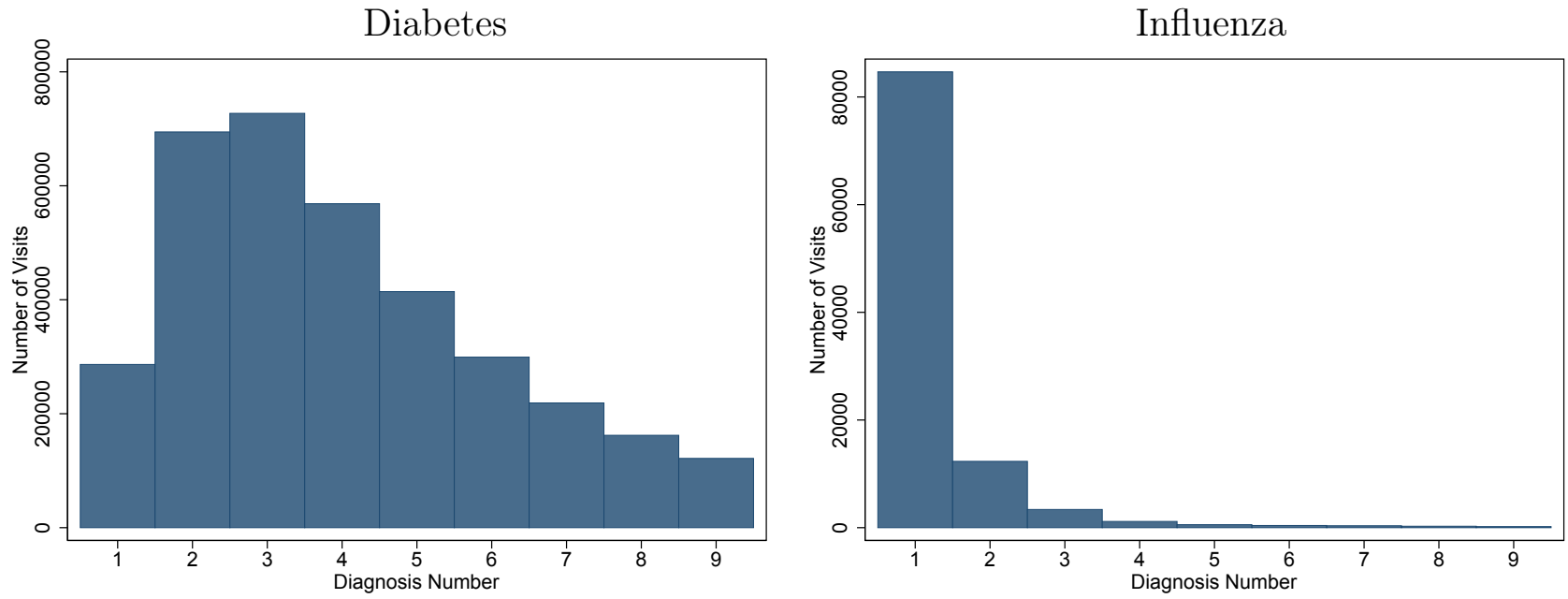

Notes: The above figures depict the frequency of all observed diagnosis positions for diabetes and influenza. That is, each figure considers all ER visits in which the diagnosis in question was recorded and displays the position in which the diagnosis appeared (i.e., " 1 " denotes the first diagnosis, " 2 " denotes the second diagnosis, etc.). 
Figure A.2: Retail Clinic Distance Group Example: North Arlington (Newark)

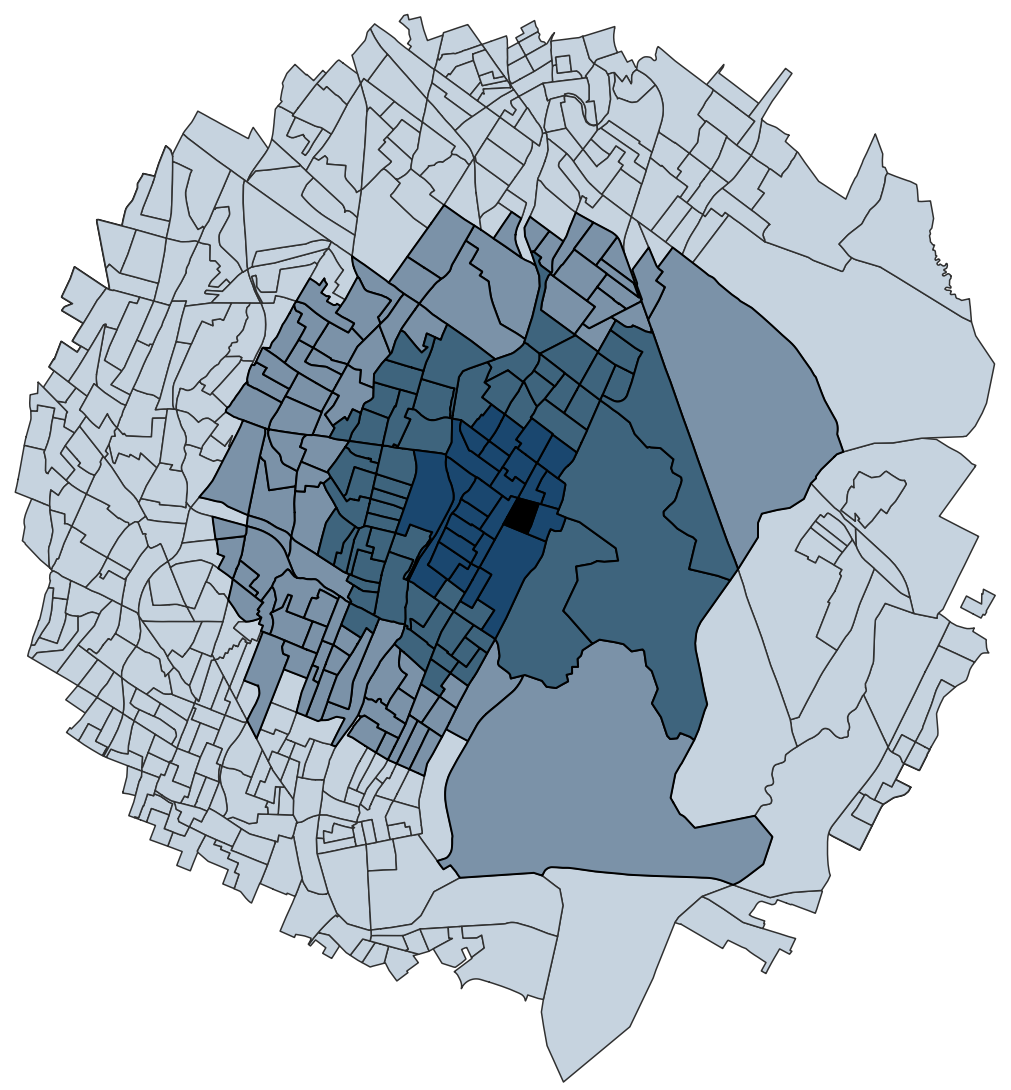

Notes: The above picture displays a close-up of the distance bands used in both our primary analysis and robustness exercises for the retail clinic located in North Arlington, New Jersey. The black block group contains the North Arlington retail clinic. The rings of block groups are shaded lighter as one moves away from the retail clinic and depict distances of 0-1 miles, 1-2 miles, 2-3 miles, and 3-5 miles from the retail clinic. 
Figure A.3: Locations of Urgent Care Clinics in 2017

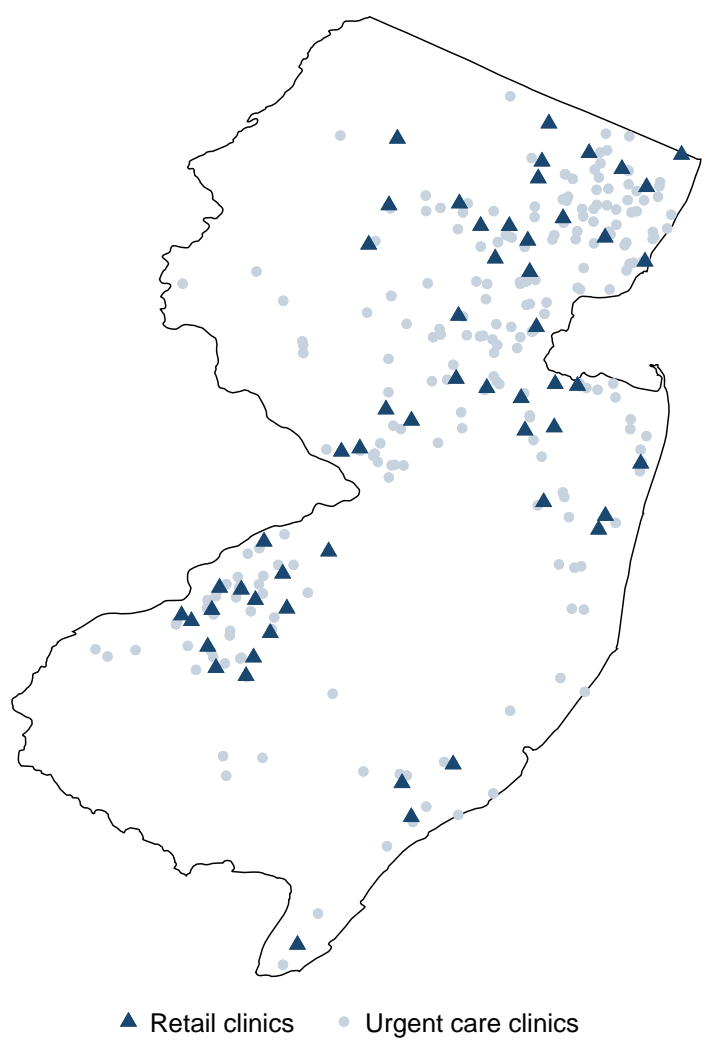

Notes: The above map displays the locations of all retail clinics in our data (triangles) and the locations of all urgent care clinics in 2017 (circles). The urgent care clinic locations in 2017 were collected by scraping google search results, and following up with each urgent care clinic's website to identify locations of all branches. 


\section{B Supplementary Tables}

Table A.1: ER Visits for Diabetes: Most Common Primary Diagnosis

\begin{tabular}{|c|c|c|c|}
\hline & Frequency & Percent & Cumulative \\
\hline Diabetes mellitus (250) & 285,743 & 8.43 & 8.43 \\
\hline Respiratory system/other chest symptoms (786) & 160,203 & 4.73 & 13.16 \\
\hline General symptoms (780) & 110,206 & 3.25 & 16.41 \\
\hline Other chronic ischemic heart disease (414) & 107,351 & 3.17 & 19.58 \\
\hline Heart failure (428) & 99,258 & 2.93 & 22.50 \\
\hline Other abdomen/pelvis symptoms (789) & 74,681 & 2.20 & 24.71 \\
\hline Other cellulitis/abscess (682) & 74,015 & 2.18 & 26.89 \\
\hline Other urinary tract disorder (599) & 65,540 & 1.93 & 28.83 \\
\hline Cardiac dysrhythmias (427) & 62,913 & 1.86 & 30.68 \\
\hline Other \& unspecified back disorder (724) & 57,266 & 1.69 & 32.37 \\
\hline Complications peculiar to certain spec. proc. (996) & 53,709 & 1.58 & 33.96 \\
\hline Acute myocardial infarct ion (410) & 50,227 & 1.48 & 35.44 \\
\hline Pneumonia, organism unspecified (486) & 50,044 & 1.48 & 36.91 \\
\hline Chronic bronchitis (491) & 45,409 & 1.34 & 38.25 \\
\hline Asthma (493) & 447,66 & 1.32 & 39.58 \\
\hline Septicemia (038) & 38,190 & 1.13 & 40.70 \\
\hline Fluid/electrolyte disorder (276) & 36,838 & 1.09 & 41.79 \\
\hline Symptoms involving head/neck (784) & 35,801 & 1.06 & 42.85 \\
\hline Osteoarthrosis \& allied disorders (715) & 35,629 & 1.05 & 43.90 \\
\hline Acute renal failure (584) & 33,229 & 0.98 & 44.88 \\
\hline Cerebral artery occlusion (434) & 32,516 & 0.96 & 45.84 \\
\hline Renal/ureteral calculus (592) & 29,667 & 0.88 & 46.71 \\
\hline Essential hypertension (401) & 29,252 & 0.86 & 47.57 \\
\hline Cataract $(366)$ & 28,985 & 0.86 & 48.43 \\
\hline Other soft tissue disorders (729) & 27,886 & 0.82 & 49.25 \\
\hline GI system symptoms (787) & 27,513 & 0.81 & 50.06 \\
\hline
\end{tabular}

Notes: The above table displays the most common primary diagnoses for hospital visits with any diabetes diagnosis recorded. Each row lists the description; the corresponding ICD-9 code is provided in parentheses. 
Table A.2: Retail Clinics and Average ER List Charges: Untrimmed Prices

\begin{tabular}{|c|c|c|c|c|}
\hline & \multirow{2}{*}{$\frac{\text { Primary Care Treatable }}{(1)}$} & \multicolumn{2}{|c|}{ Emergent, Preventable } & \multirow{3}{*}{ 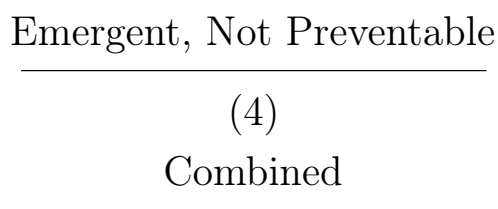 } \\
\hline & & (2) & (3) & \\
\hline & Combined & Influenza & Diabetes & \\
\hline \multirow[t]{2}{*}{ Open } & 10.096 & -287.840 & -320.411 & 0.569 \\
\hline & $(73.543)$ & $(980.343)$ & $(350.802)$ & $(328.006)$ \\
\hline \multirow[t]{2}{*}{ Near } & -104.187 & $-2,170.106$ & -489.617 & -402.278 \\
\hline & (180.333) & $(1,317.644)$ & (430.300) & (322.448) \\
\hline \multirow[t]{2}{*}{ Open*Near } & $474.526^{*}$ & $1,863.661$ & 824.956 & 412.784 \\
\hline & $(282.555)$ & $(1,238.487)$ & $(667.641)$ & $(449.641)$ \\
\hline Mean per $100 \mathrm{k}$ & $4,030.004$ & $8,047.146$ & $34,139.164$ & $19,637.637$ \\
\hline Mean Pop. & 175,121 & 175,121 & 175,121 & 175,121 \\
\hline R-Squared & 0.484 & 0.037 & 0.394 & 0.547 \\
\hline Observations & 51,480 & 51,480 & 51,480 & 51,480 \\
\hline
\end{tabular}

*** $\mathrm{p}<0.01,{ }^{* *} \mathrm{p}<0.05,{ }^{*} \mathrm{p}<0.1$

Notes: Observations are at the retail clinic-distance band-week level. The independent variable in each regression is the average total list charges of ER visits for a given condition. All regressions include month, year, and retail clinic fixed effects and are population weighted. Additional retail clinic-distance group controls include population density, fraction black, a quadratic in median household income, and the age structure. Standard errors are clustered by retail clinic. 
Table A.3: Retail Clinics and Average ER List Charges: Residualized Prices

\begin{tabular}{lcccccc}
\hline \multicolumn{7}{c}{ Primary Care Treatable } \\
\cline { 2 - 7 } & $(1)$ & $(2)$ & $(3)$ & $(4)$ & $(5)$ & $(6)$ \\
& UTI & Conjunct. & URTI & Pharyngitis & Otitis & Sprain/strain \\
\hline Open & -280.392 & 29.458 & 154.586 & 52.962 & 54.008 & -6.126 \\
& $(197.169)$ & $(69.217)$ & $(133.758)$ & $(79.129)$ & $(78.472)$ & $(85.581)$ \\
Near & $-677.494^{* * *}$ & -82.697 & -131.861 & -144.213 & -104.856 & -112.172 \\
& $(223.223)$ & $(111.229)$ & $(153.679)$ & $(108.170)$ & $(112.123)$ & $(114.621)$ \\
Open*Near & $952.289^{* *}$ & 161.852 & $615.495^{* *}$ & 305.274 & 346.609 & 274.012 \\
& $(397.480)$ & $(208.919)$ & $(302.572)$ & $(221.984)$ & $(222.429)$ & $(233.502)$ \\
\hline Mean per 100k & -11.948 & 29.194 & 210.073 & 25.170 & 105.067 & 26.844 \\
Mean Pop. & 175,121 & 175,121 & 175,121 & 175,121 & 175,121 & 175,121 \\
R-Squared & 0.044 & 0.016 & 0.047 & 0.123 & 0.064 & 0.281 \\
Observations & 51,476 & 51,477 & 51,473 & 51,477 & 51,473 & 51,474 \\
\hline \hline
\end{tabular}

\begin{tabular}{|c|c|c|c|c|c|}
\hline & \multicolumn{2}{|c|}{ Emergent, Preventable } & \multicolumn{3}{|c|}{ Emergent, Not Preventable (Placebo) } \\
\hline & (1) & (2) & (3) & (4) & (5) \\
\hline & Influenza & Diabetes & Fractures & Poisonings & Births \\
\hline \multirow[t]{2}{*}{ Open } & $4,019.556$ & -22.988 & -51.293 & 166.862 & 186.730 \\
\hline & $(2,848.726)$ & $(436.149)$ & $(263.449)$ & $(429.721)$ & $(466.919)$ \\
\hline \multirow[t]{2}{*}{ Near } & -370.052 & -451.070 & $-569.792^{*}$ & 104.494 & -258.234 \\
\hline & $(4,649.174)$ & $(457.218)$ & $(294.849)$ & $(624.785)$ & $(252.725)$ \\
\hline \multirow[t]{2}{*}{ Open*Near } & $-7,730.023$ & $1,090.283$ & 472.349 & 376.180 & 456.116 \\
\hline & $(5,222.984)$ & $(914.503)$ & $(526.075)$ & $(810.051)$ & $(500.814)$ \\
\hline Mean per $100 \mathrm{k}$ & $-1,192.490$ & -152.406 & -33.930 & 155.379 & 36.936 \\
\hline Mean Pop. & 175,121 & 175,121 & 175,121 & 175,121 & 175,121 \\
\hline R-Squared & 0.046 & 0.247 & 0.065 & 0.030 & 0.376 \\
\hline Observations & 51,480 & 51,479 & 51,471 & 51,472 & 51,475 \\
\hline
\end{tabular}

${ }^{* * *} \mathrm{p}<0.01,{ }^{* *} \mathrm{p}<0.05,{ }^{*} \mathrm{p}<0.1$

Notes: Observations are at the retail clinic-distance band-week level. The independent variable in each regression is the average total list charges of ER visits for a given condition residualized from hospital fixed effects and an indicator for whether the patient was admitted. All regressions include month, year, and retail clinic fixed effects and are population weighted. Additional retail clinic-distance group controls include population density, fraction black, a quadratic in median household income, and the age structure. Standard errors are clustered by retail clinic. "UTI" denotes urinary tract infections; "URTI" denotes upper respiratory tract infections. 
Table A.4: Distribution of List Charges by Diagnosis

\begin{tabular}{lcccccccc}
\hline & $\mathrm{p} 5$ & $\mathrm{p} 25$ & $\mathrm{p} 50$ & $\mathrm{p} 75$ & $\mathrm{p} 95$ & Mean & Std. Dev. & Count \\
\hline Influenza & 495 & 1054 & 1787 & 3348 & 29425 & 6688.63 & 25927.55 & 82,676 \\
Diabetes & 895 & 3258 & 14527 & 42429 & 116862 & 32402.23 & 53472.52 & $3,389,333$ \\
Urinary tract infection & 663 & 1396 & 2934 & 9220 & 53504 & 11773.92 & 26540.98 & 660,532 \\
Conjunctivitis & 293 & 513 & 785 & 1193 & 3145 & 1222.62 & 2364.37 & 178,601 \\
URTI/sinusitis/bronchitis & 373 & 776 & 1335 & 2387 & 12420 & 3322.52 & 9624.29 & $1,220,564$ \\
Pharyngitis & 352 & 680 & 1046 & 1659 & 4446 & 1708.13 & 3428.79 & 528,145 \\
Otitis & 322 & 575 & 913 & 1415 & 6003 & 1728.56 & 4434.3 & 535,466 \\
Sprains \& strains & 555 & 1034 & 1589 & 2378 & 7997 & 2666.38 & 7047.24 & $1,673,502$ \\
Poisonings & 404 & 1086 & 2847 & 12874 & 64116 & 14797.16 & 41404.47 & 204,605 \\
Fractures & 802 & 1477 & 2523 & 11990 & 78526 & 17611.13 & 53310.2 & $1,120,181$ \\
Births & 9108 & 15311 & 20730 & 27729 & 42460 & 22939.67 & 14193.1 & 854,560 \\
\hline
\end{tabular}

Notes: The above table presents summary statistics for list charges by diagnosis across hospital visits.

Table A.5: CVS MinuteClinic Price List

\begin{tabular}{lc}
\hline & Posted price \\
\hline General medical exams & 89 \\
Minor illnesses & $89-129$ \\
Minor injuries & $89-129$ \\
Adeno test (viral pink eye) & 25 \\
Blood sugar test & 25 \\
Flu test (A/B) & 35 \\
Strep test (rapid) & 35 \\
Diabetes monitoring & $79-99$ \\
Diabetes screening (glucose) & $59-69$ \\
Influenza vaccine (high dose) & 69.99 \\
Influenza vaccine (seasonal) & 44.99 \\
\hline
\end{tabular}

Notes: The above prices come from www.cvs.com/minuteclinic; last accessed May 2017. Minor illnesses include urinary tract and bladder infections, upper respiratory infections, sore and strep throat, and earaches and ear infections. Minor injuries include sprains, strains, and joint pain. High dose influenza vaccines contain more antigen and are intended to create a stronger immune response; these vaccines are available for people aged 65 years and older (CDC). 